\title{
Overconfidence, Compensation Contracts, and Capital Budgeting
}

\author{
SIMON GERVAIS, J. B. HEATON, and TERRANCE ODEAN*
}

\begin{abstract}
A risk-averse manager's overconfidence makes him less conservative. As a result, it is cheaper for firms to motivate him to pursue valuable risky projects. When compensation endogenously adjusts to reflect outside opportunities, moderate levels of overconfidence lead firms to offer the manager flatter compensation contracts that make him better off. Overconfident managers are also more attractive to firms than their rational counterparts because overconfidence commits them to exert effort to learn about projects. Still, too much overconfidence is detrimental to the manager since it leads him to accept highly convex compensation contracts that expose him to excessive risk.
\end{abstract}

A VAST EXPERIMENTAL LiteratURE finds that individuals are usually overconfident in that they believe their knowledge to be more precise than it actually is. The incidence of overconfidence is likely to be even greater among CEOs than among individuals at large; for example, Goel and Thakor (2008) show that overconfident individuals are more likely to win the intrafirm tournaments that lead to the rank of CEO. Since overconfidence directly influences decision-making, it is logical to investigate the effects that overconfident managers have on corporate policies and firm value. How does overconfidence affect the investment decisions that managers make on behalf of shareholders? How do compensation contracts optimally adjust to these effects? Do firms benefit from managerial overconfidence? Can overconfidence ever benefit the biased

*Simon Gervais is from Duke University. J. B. Heaton is from Bartlit Beck Herman Palenchar $\&$ Scott LLP. Terrance Odean is from the University of California at Berkeley. This paper is an updated version of a previous working paper, "Overconfidence, Investment Policy, and Manager Welfare," by the same authors. The authors would like to thank Franklin Allen, Jonathan Berk, Bruce Carlin, David Denis, Robert Goldstein, David Ross, Jacob Sagi, Marti Subrahmanyam, Peter Swan, two anonymous referees, and the Acting Editor, David Hirshleifer, for their comments and suggestions. Also providing useful comments and suggestions were seminar participants at the Meetings of the European Finance Association, the Meetings of the American Finance Association, the NYU Stern Five Star Conference on Research in Finance, the Laurier Finance Conference, the Conference of the Financial Intermediation Research Society, Baruch College, Cornell University, Emory University, Insead, London Business School, London School of Economics, the University of Amsterdam, the University of British Columbia, the University of California at Los Angeles, the University of Florida, the University of Maryland, the University of Minnesota, the University of Oregon, the University of Toronto, Vanderbilt University, and the Wharton School. J. B. Heaton acknowledges that the opinions expressed here are his own, and do not reflect the position of Bartlit Beck Herman Palenchar \& Scott LLP or its attorneys. All remaining errors are the authors' responsibility. 
manager himself? How does labor market structure influence the effects of overconfidence?

We develop a model of capital budgeting that enables us to answer these questions by contrasting the decisions of overconfident managers with those of rational managers. In our model, a risk-neutral firm hires a risk-averse manager to make an investment decision on its behalf. The manager is skilled in that he has private access to a noisy signal about the quality of the new project before he decides whether to invest in it. An overconfident manager overestimates the precision of his signal, and so is overly inclined to undertake (abandon) the project when his information is positive (negative). In a context where the manager is both risk-averse and overconfident, the compensation contract that maximizes shareholder wealth serves two purposes: to increase the manager's appetite for undertaking risky projects, and to curb the impetuousness that his overconfidence creates. We analyze this contracting problem first in a setting where the manager's opportunities outside the firm are exogenously fixed, and then in a labor market equilibrium that endogenizes the manager's reservation utility.

When the manager's outside opportunities are fixed, the firm captures the entire economic surplus that the manager's skill creates. We show that this surplus is increasing in the manager's overconfidence. The inability to diversify their human capital causes risk-averse managers to act more conservatively than is in the best interests of shareholders (e.g., Jensen and Meckling (1976), Treynor and Black (1976)). Because overconfident managers overestimate the amount of risk that their information eliminates, they are less prone to this conservatism. The form of compensation contract that is offered by the firm depends on the degree of the manager's overconfidence. If the manager is mildly overconfident, the firm increases its value by reducing the convexity of his compensation contract relative to a rational manager's contract. In this case, less performance-based compensation (e.g., bonuses, stocks, and options) is required to realign the manager's incentives to undertake valuable risky projects because the overconfident manager perceives less risk. If, instead, the manager is extremely overconfident, the firm takes advantage of his bias by offering him a highly convex contract that he overvalues. The performance-based compensation then further benefits the firm by allowing it to arbitrage the manager's excessive beliefs that his decisions will lead to good outcomes.

When a competitive labor market is introduced into the model, firms must compete to hire managers who then capture some of the economic surplus they create. In this context, we show that an overconfident manager may benefit from his own bias; that is, he may end up capturing more economic surplus than an otherwise identical but rational manager does. The realization of this benefit depends upon the degree of the manager's overconfidence and the set of firms that seek to hire him. When similar firms compete for the services of a mildly overconfident manager, they rely on the manager's overconfidence to guarantee his commitment to undertake valuable risky projects. A modest amount of performance-based compensation is then sufficient to realign the manager's incentives, and the firms end up competing to attract him by 
increasing the safer portion of his compensation. In equilibrium, the overconfident manager's compensation is closer to first-best, and he is better off than his rational counterpart. Specifically, the manager's overconfidence allows for a more efficient transfer of economic surplus via a flatter schedule that improves the risk-sharing arrangement between the manager and the winning bidder.

If the manager's overconfidence is extreme, however, it becomes optimal for the firms to compete for his services by increasing his performance-based compensation. In this case, the manager overvalues this type of compensation to such an extent that firms gain from shifting risk onto the manager. This always makes the manager worse off. These results complement the work of Goel and Thakor (2008), who show that moderate levels of manager overconfidence benefit the firm, while extreme levels of overconfidence are detrimental. Our analysis shows that the presence of labor markets leads to similar results about the welfare of managers.

When the firms competing for the manager's services differ in their growth prospects and risk, the eventual matching of managers with firms depends on the manager's overconfidence. Rational and mildly overconfident managers are more likely to end up working at safe, diversified, value firms that offer relatively flat compensation contracts. In contrast, highly overconfident managers are likely to be attracted by the compensation convexity that risky, focused, growth firms can offer. Our model thus predicts that changes in the crosssectional composition of labor and compensation contracts vary with changes in firms' investment opportunity sets (e.g., resulting from the emergence of a new growth industry), changes in individual overconfidence (e.g., resulting from self-attribution bias), and the extent of competition for a given skill (e.g., individuals with industry-specific skills do not attract bidders from other industries to the extent that individuals with general, portable skills do).

Finally, we show that managerial overconfidence can serve as a commitment to exert costly effort. In this final extension of the model, compensation contracts must serve a dual purpose, as in the work of Lambert (1986), Hirshleifer and Suh (1992), and Diamond (1998): to realign the manager's incentives to make investment decisions in the shareholders' interest, and to ensure that the manager exerts the effort necessary to investigate investment opportunities. Our analysis departs from earlier studies by adding managerial overconfidence to this dual agency problem. Because overconfident managers overvalue the benefit of the effort needed to learn about risky projects, they can be motivated to exert this effort more easily than rational managers. In some cases, dual realignment is only possible with overconfident managers and so hiring these managers, as opposed to otherwise identical but rational managers, becomes a priority for firms. This again benefits managers who exhibit some overconfidence.

Although a large body of theoretical literature studies the implications of overconfidence for financial markets, ${ }^{1}$ relatively few theoretical studies look at

\footnotetext{
${ }^{1}$ See Hirshleifer (2001) for a survey of this literature.
} 
overconfidence in corporate settings. ${ }^{2}$ Roll (1986) suggests that overconfidence (hubris) may motivate many corporate takeovers. His conjecture that successful investments require CEO skill and some risk-taking is consistent with our model. As we show, however, the conclusion that overconfidence leads to overinvestment implicitly relies on suboptimal contractual arrangements between the firm and its decision-makers. Our analysis departs from the existing literature by assuming that firms can identify overconfident managers and therefore adjust their contracts to properly account for their biases. In this context, the incidence of overinvestment need not be affected by overconfidence, and more economic surplus can sometimes be shared by the firm and the agent. ${ }^{3}$

Building on the work of Fershtman and Judd (1987) and Sklivas (1987) about the optimal incentives of agents whose firms compete in product markets, Englmaier (2006) shows that overconfidence commits agents to be more aggressive, making their firm more profitable in the process. ${ }^{4}$ Hackbarth (2008) finds that managerial overconfidence leads to greater debt financing and that overconfidence, by acting as a commitment device, can also ameliorate bondholder and shareholder conflicts such as debt overhang. Our paper differs from these in that we consider the interaction of the manager's bias with the compensation contract and incentives provided by his firm.

The work of Adrian and Westerfield (2009) and Palomino and Sadrieh (2011) is also related to this paper. Adrian and Westerfield (2009) develop a model of dynamic contracting with disagreement and learning, and show that there are gains from shifting the agent's consumption-via contracting-to states the agent considers more likely. Palomino and Sadrieh (2011) show how the principal can benefit from the agent's overconfidence in a delegated portfolio management setting if he knows that the agent is overconfident. Like these papers, we also show that the principal can benefit from the agent's overconfidence via contracting when he is aware of the agent's overconfidence. The difference is that we focus our analysis on capital budgeting issues and examine the labor market conditions under which the agent also benefits from his overconfidence.

Most closely related to our paper is the work of Goel and Thakor (2008). They model the firm's internal promotion process as an intrafirm tournament and show that overconfident managers are more likely than rational managers

\footnotetext{
${ }^{2}$ Our notion of overconfidence captures the idea that individuals overestimate the precision of their information or their ability to interpret that information when they make economic decisions. A related concept is the idea that people are optimistic in the sense that they expect future outcomes to be better than they really are. Such a bias has been studied in the context of financial intermediation (Manove and Padilla (1999), Coval and Thakor (2005)), entrepreneurship (Landier and Thesmar (2009)), and capital budgeting (Heaton (2002)), among others. For surveys of the effects of behavioral biases in corporate finance, see Baker, Ruback, and Wurgler (2007) and Gervais (2010).

3 This possibility is in fact documented by Graham, Li, and Qiu (2012), who find that manager fixed effects explain over half of the variation in executive compensation. They also show that these fixed effects relate to unobservable manager characteristics, which may include skill, risk aversion, and overconfidence.

${ }^{4}$ Kyle and Wang (1997) make a similar point in the context of money management.
} 
to be promoted to CEO. One of their main results, namely, that increases in managerial overconfidence lead to higher firm value but only up to a point (after which excessive overconfidence destroys firm value), is also encountered in our analysis. The key differences are threefold. First, in contrast to that paper, we assume that firms know they are dealing with overconfident managers and thus write incentive contracts accordingly, that is, we focus on the design of optimal contracts when the principal can distinguish among rational and overconfident agents. Second, we show that the result that an overconfident manager is made worse off by his bias, a finding common to most papers in the literature, is a special case. Specifically, this result occurs only when the structure of the labor market is such that all the surplus created by the manager's overconfidence goes to the firm. In the more general case in which the surplus is shared, both the firm and the manager can benefit from managerial overconfidence. Third, unlike the previous literature, we also examine how CEOs are matched with firms based on both managerial overconfidence and firm attributes. For example, our model shows that the most overconfident executives will tend to end up in risky growth firms, as documented by Graham, Harvey, and Puri (2009). ${ }^{5}$

Recent empirical studies also document the presence of managerial overconfidence and its effects on corporate policies. For example, Malmendier and Tate (2005, 2008) use the tendency of CEOs to delay the exercise of their stock options to proxy for overconfidence, and show that this measure correlates with the intensity of firm investments. Ben-David, Graham, and Harvey (2010) and Sautner and Weber (2009) use survey evidence to show that the overconfidence of top executives affects various corporate decisions, including the investment policy of the firm. Liu and Taffler (2008) use formal content analysis of CEO statements to measure CEO overconfidence, and find that high ratings of this measure correlate with investment activity. As we show, overconfidence coupled with inefficient contracting can lead to overinvestment. However, when contracts optimally consider overconfidence, our model makes a number of new empirical predictions that are readily testable using the same data as in these existing studies. For example, our model predicts that overconfident executives should receive more performance-based compensation than their rational counterparts in young, risky, growth firms and less performance-based compensation in older, safer, value firms.

The rest of our paper proceeds as follows. Section I introduces the model, presents the first-best solution, and solves the firm's problem of choosing a value-maximizing compensation contract. In Section II, we introduce labor market considerations and show how overconfidence can end up benefiting the manager. Section III provides an extension of our model that accommodates moral hazard resulting from costly effort. Finally, Section IV summarizes our findings and concludes. All the proofs are contained in Appendix A.

\footnotetext{
${ }^{5}$ Our work also complements that of Bernardo and Welch (2001), who provide an evolutionary rationale for the presence of overconfident entrepreneurs in a society, and that of Wang (2001), who shows how overconfident traders can survive in the long run.
} 


\section{The Model}

In this section, we introduce our formal model and analyze the effects of managerial overconfidence on the firm's investment policy. We then characterize optimal compensation contracts for given levels of managerial skill, overconfidence, and risk aversion, and provide comparative statics on how contract terms change with these managerial attributes. Until Section II, we assume that the manager's reservation utility is specified exogenously, as in standard principal-agent models.

\section{A. The Firm and Its Manager}

An all-equity firm initially consists of one dollar in cash and is considering investing this money in a one-period risky project. To make the investment decision on behalf of the risk-neutral shareholders, the firm hires a manager whose skills potentially add value to the project. In what follows, we describe the project, the information technology used to assess the project's value, the compensation contract offered by the firm, and the manager's preferences and overconfidence.

\section{A.1. The Project}

The project requires an investment of one dollar. Its end-of-period cash flow is denoted by the random variable $\tilde{v}$, whose prior distribution is public knowledge and is given $b^{6}$

$$
\tilde{v}=\left\{\begin{array}{l}
\sigma, \text { prob. } \phi \\
0, \text { prob. } 1-\phi,
\end{array}\right.
$$

where $\sigma>1$ and $\phi \in(0,1)$. For simplicity, we assume that the appropriate discount rate for these cash flows is zero. We also assume that $\sigma \phi<1$ so that, without the benefit of any additional information about $\tilde{v}$, the net present value (NPV) of the project is negative.

\section{A.2. Information Technology and the Manager's Skills}

The potential value of the project comes from the manager's ability to gather additional information about it and to use this information to make the investment decision on behalf of the shareholders. We assume that the manager has access to a private signal $\tilde{s} \in\{0, \sigma\}$ that is informative about $\tilde{v}$ but that is unobservable to the firm. ${ }^{7}$ This signal is given by $\tilde{s}=\tilde{\varepsilon} \tilde{v}+(1-\tilde{\varepsilon}) \tilde{\eta}$, where $\tilde{\varepsilon}$ is equal to one with probability $a \in\left[0, \frac{1}{2}\right]$ and equal to zero with probability $1-a$,

\footnotetext{
${ }^{6}$ All variables with a tilde are random variables. All the other variables are constants whose values are public knowledge.

${ }^{7}$ For now, we assume that this signal is costless and so always observed by the manager. Our results are unchanged if the manager must pay a utility cost for his effort to acquire $\tilde{s}$. For ease of exposition, however, we postpone our treatment of costly effort until Section III.
} 
and where $\tilde{\eta}$ has the same distribution as $\tilde{v}$ but is independent from it. Because $\tilde{\varepsilon}$ is unobservable (by either the firm or the manager), the signal is more useful when $a$ is large, as $\tilde{s}$ is then more likely to have come from $\tilde{v}$ than from noise $(\tilde{\eta})$. Thus, we can think of $a$ as the manager's true skill.

\section{A.3. Compensation Contract}

If the risky project is undertaken, the firm ends the period with zero or $\sigma>1$; otherwise, it ends the period with its initial cash position of one dollar. These three outcomes represent the only three possible states of nature, and all compensation contracts between the firm and its manager must be written as a function of these states, which we refer to as low, medium, and high (for values of zero, one, and $\sigma$, respectively). We denote the manager's compensation in each of these states by $\left\{\delta_{\mathrm{L}}, \delta_{\mathrm{L}}+\delta_{\mathrm{M}}, \delta_{\mathrm{L}}+\delta_{\mathrm{M}}+\delta_{\mathrm{H}}\right\}$; that is, $\delta_{\mathrm{M}}$ is the increment in compensation from the low to the medium state, and $\delta_{\mathrm{H}}$ is the increment in compensation from the medium to the high state.

The manager is assumed to have zero wealth and, like the firm's shareholders, is protected by limited liability. Therefore, his compensation in all three states is restricted to be nonnegative and, because the firm is worthless after a failed risky project, we must have $\delta_{\mathrm{L}}=0$. As a result, in what follows we denote compensation contracts simply by $\left\{\delta_{\mathrm{M}}, \delta_{\mathrm{H}}\right\}$. The manager effectively controls the risk of his own compensation through his investment decisions. Thus, we can think of $\delta_{\mathrm{M}}$ as the present value of the compensation that the manager can expect if he puts the firm on a safe investment trajectory using a status quo strategy, and $\delta_{\mathrm{H}}$ as the present value of the extra compensation that the manager will receive over his career for successfully altering the firm's investment policy at the risk of potentially losing $\delta_{\mathrm{M}}$ to bad outcomes. ${ }^{8}$

\section{A.4. The Manager's Preferences}

We assume that the manager is risk-averse. To keep the analysis tractable, we model risk aversion as a constant reduction $r \in[0,1)$ in marginal utility between the medium outcome and the high outcome. More precisely, the manager is assumed to get a boost in utility of only $(1-r) \delta_{\mathrm{H}}$ when he undertakes a successful risky project for his firm instead of sticking with a risk-free investment. Thus, the manager's utility in each of the three states is $\left\{0, \delta_{\mathrm{M}}, \delta_{\mathrm{M}}+(1-r) \delta_{\mathrm{H}}\right\}$. This effectively makes him risk-averse: as with standard utility functions, the manager's utility increases more rapidly for low levels of compensation

\footnotetext{
${ }^{8}$ The fact that the firm is worthless and the manager does not get paid after a failed project is meant to capture the idea that managers and CEOs face a greater risk of being replaced when the investments they make do not pan out (e.g., Warner, Watts, and Wruck (1988), Weisbach (1988)) and even a flat compensation stream is curtailed when replacement does occur. For example, even though we do not formally model the possibility of bankruptcy and takeovers, the human capital risks associated with these events are well documented (e.g., Agrawal and Knoeber (1998), Eckbo and Thorburn (2003)).
} 
(i.e., for compensation below $\delta_{M}$ ) than for high levels of compensation (above $\left.\delta_{\mathrm{M}}\right)^{9}$

\section{A.5. The Manager's Overconfidence}

We assume that the manager is potentially overconfident in that he overestimates his own skill by $b \in\left[0, \frac{1}{2}\right]$. Specifically, although the firm knows the manager's skill and overconfidence to be $a$ and $b$, respectively, the manager thinks that he is rational and that his skill is $a+b$. That is, the manager overestimates the informativeness of his signal. The following lemma calculates the manager's posterior beliefs about the distribution of $\tilde{v}$.

LEMMA 1: After the manager receives a positive signal $\tilde{s}=\sigma$, his posterior beliefs about $\tilde{v}$ are given by ${ }^{10}$

$$
\hat{\operatorname{Pr}}\{\tilde{v}=\sigma \mid \tilde{s}=\sigma\}=\phi+(a+b)(1-\phi) \equiv \hat{\phi}_{\mathrm{U}} .
$$

After the manager receives a negative signal $\tilde{s}=0$, his posterior beliefs about $\tilde{v}$ are given by

$$
\hat{\operatorname{Pr}}\{\tilde{v}=\sigma \mid \tilde{s}=0\}=(1-a-b) \phi \equiv \hat{\phi}_{\mathrm{D}} .
$$

Because the correlation between $\tilde{s}$ and $\tilde{v}$ is equal to $a$, the manager's signal is always informative unless he is completely unskilled (i.e., $a=0$ ). ${ }^{11}$ Specifically, the posterior probability that $\tilde{v}=\sigma$ after the manager receives a positive signal $\tilde{s}=\sigma$ (negative signal $\tilde{s}=0$ ) is greater (smaller) than the prior probability $\phi$, regardless of his overconfidence $b$. Also, $\hat{\phi}_{\mathrm{U}}$ is increasing in $b$ and $\hat{\phi}_{\mathrm{D}}$ is decreasing in $b$, as the overconfident manager puts too much weight on his information and thinks that the project is better (worse) than it really is after observing $\tilde{s}=\sigma(\tilde{s}=0)$. In what follows, we remove the hats to denote the correct beliefs of a rational manager (i.e., a manager with $b=0$ ); for example, we use $\phi_{\mathrm{U}}=\phi+a(1-\phi)$ and $\phi_{\mathrm{D}}=(1-a) \phi$.

\section{A.6. Summary and Timeline}

To sum up, the unconditional distribution of the project's end-of-period cash flow, $\tilde{v}$, is known to both the firm and the manager. The signal $\tilde{s}$ is known only to the manager and is not verifiable by the firm. The manager's actual skill

\footnotetext{
${ }^{9}$ With this three-outcome specification, assuming more traditional utility functions would not affect any of our results. However, this specification allows us to derive all of our results in closed form. Our approach to modeling risk aversion is similar to that of Dow (2004) in that we assume a piecewise-linear utility function with a single kink at the status quo (since the manager collects $\delta_{\mathrm{M}}$ with probability one if he does not alter the firm's existing investment policy).

${ }^{10}$ Throughout the paper, hatted probabilities $(\hat{\operatorname{Pr}})$ and variables are used to denote the fact that the manager's beliefs are biased.

11 To see this, note that $\operatorname{Cov}(\tilde{s}, \tilde{v})=\operatorname{Pr}\{\tilde{\varepsilon}=1\} \operatorname{Cov}(\tilde{v}, \tilde{v})+\operatorname{Pr}\{\tilde{\varepsilon}=0\} \operatorname{Cov}(\tilde{\eta}, \tilde{v})=a \operatorname{Var}(\tilde{v})+(1-$ $a)(0)=a \operatorname{Var}(\tilde{v})$. Since $\operatorname{Var}(\tilde{s})=\operatorname{Var}(\tilde{v})$, the correlation between $\tilde{s}$ and $\tilde{v}$ is equal to $\frac{a \operatorname{Var}(\tilde{v})}{\operatorname{Var}(\tilde{v})}=a$.
} 


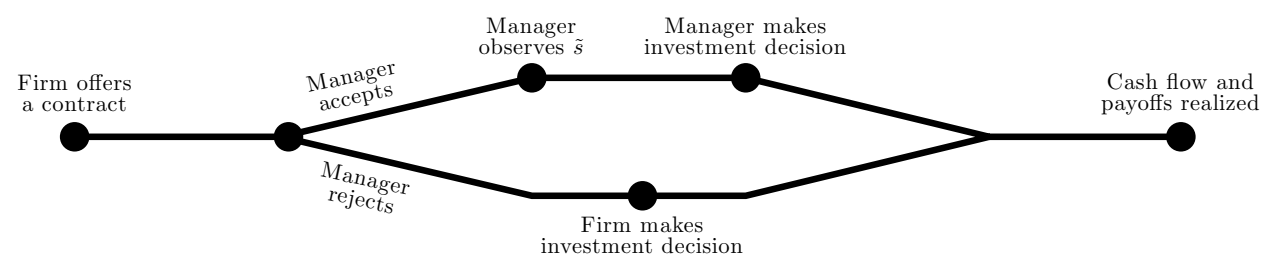

Figure 1. Sequence of events. In each period, the firm offers a compensation contract to the manager, who can accept or reject it. If the manager accepts, he receives a private signal ( $\tilde{s})$ about the project's end-of-period cash flow ( $\tilde{v})$ and makes the investment decision on behalf of the firm's shareholders. Otherwise, the firm makes its own investment decision. The project's cash flow and all payoffs are realized at the end of the period.

level, $a$, as well as the manager's overconfidence level, $b$, are known to the firm, but the manager believes that his skill is $a+b$ and that he is rational. ${ }^{12}$

The sequence of events is illustrated in Figure 1. The firm offers the manager a compensation contract. If the manager accepts the contract, he observes a private signal $(\tilde{s})$ about the end-of-period payoff of the project $(\tilde{v})$ and makes the investment decision for the firm. If the manager rejects the contract, the firm makes its own investment decision (and so does not invest in the project, as its NPV without the knowledge of $\tilde{s}$ is negative). If the project is undertaken, its end-of-period cash flow is realized and observed by the firm and the manager. Finally, the manager receives his compensation and the firm's shareholders receive the net profit.

\section{B. First-Best}

Before we turn to the manager's decisions and associated agency problems, let us characterize the investment policy that maximizes total surplus absent any agency friction between the firm and the manager. In this first-best solution, the firm invests according to a policy that makes optimal use of the manager's information in order to maximize firm value. Because the manager is biased, he may disagree with the firm's shareholders about this policy. We calculate the surplus using the beliefs of a rational manager, as this is the surplus that is available ex post (on average) and from which the manager ultimately derives his utility. ${ }^{13}$

Since $E[\tilde{v}]-1=\sigma \phi-1<0$, only a positive signal can potentially justify an investment in the project. Indeed, because $\phi_{\mathrm{D}}<\phi$, it is always optimal for the firm to drop the project when $\tilde{s}=0$, as $E[\tilde{v} \mid \tilde{s}=0]-1=\sigma \phi_{\mathrm{D}}-1<\sigma \phi-1<0$.

\footnotetext{
${ }^{12}$ In reality, firms' assessments of managerial skill and overconfidence are noisy. However, adding noise to $a$ and $b$ unnecessarily complicates our model, without qualitatively changing its implications. Kaplan, Klebanov, and Sorensen (2008) document that firms actively assess the skills as well as the behavioral attributes of the executives they hire.

${ }^{13}$ For simplicity, we describe the first-best policy under the assumption that the entire surplus accumulates to the firm, which is equivalent to assuming a reservation utility of zero for the manager.
} 
With $\tilde{s}=\sigma$, the firm undertakes the project as long as $E[\tilde{v} \mid \tilde{s}=\sigma]-1=\sigma \phi_{\mathrm{U}}-$ $1>0$, which, using (1), can be shown to be equivalent to $a>1-\frac{\sigma-1}{\sigma(1-\phi)}$. In other words, the manager's information adds value only if he is skilled enough. The following lemma characterizes the first-best investment policy of the firm and the associated firm value.

LEMMA 2 (First-Best): If the manager's skill level is sufficiently high, that is, if $a>1-\frac{\sigma-1}{\sigma(1-\phi)} \equiv a^{\mathrm{FB}}$, then the project is undertaken if and only if a positive signal $(\tilde{s}=\sigma)$ is observed, and the value of the firm is given by

$$
F^{\mathrm{FB}}=1+\phi\left(\sigma \phi_{\mathrm{U}}-1\right)=1-\phi+\sigma \phi[\phi+a(1-\phi)] .
$$

If the manager's skill level is low, that is, if $a \leq a^{\mathrm{FB}}$, then the project is never undertaken and the firm's value is one.

When the manager is sufficiently skilled, the firm's first-best investment decision is based on his information. As can be seen from (3), the resulting value of the firm is increasing in $a$, as the odds that the manager's information is correct are better when $a$ is large. Also, it is easy to verify that the skill $a^{\mathrm{FB}}$ required for the manager's information to be valuable is decreasing in $\sigma$ and $\phi$ : projects that initially look promising do not require as much managerial input.

In short, because the no-information NPV of the project is negative, the default strategy of the firm is the status quo strategy, in which the firm adds no risk to its existing business. New projects are only considered if the available information makes the additional risk worthwhile. ${ }^{14}$

\section{The Manager's Investment Decisions}

As in the work of Holmström and Ricart i Costa (1986), the manager's risk aversion creates preference incongruities between him and the firm's shareholders. Whereas shareholders want the firm to invest in any positive-NPV project (i.e., projects for which $\tilde{s}=1$, as long as $a>a^{\mathrm{FB}}$ ), a sufficiently riskaverse manager would not follow the same investment rule absent contractual incentives, which we study in this section. Our analysis departs from Holmström and Ricart i Costa (1986) in that we add overconfidence as a trait that

\footnotetext{
${ }^{14}$ Note that the assumption that the no-information NPV of the project is negative implicitly serves another purpose: it captures the idea that competition for positive-NPV projects is often intense within an industry. Indeed, as the simple model that we include in Appendix B shows, the amount of competition within an industry will essentially reduce the set of projects for which information gathering is possible when other firms that do not spend as much time gathering information can steal the project away. A project whose expected cash flow $\sigma \phi$ is far above the initial investment of one dollar is so appealing to all the firms in an industry that no firm that takes the time to learn more about the project ever ends up beating the other firms to it. As the competition intensifies, more projects satisfying $\sigma \phi>1$ are undertaken without information. Thus, our assumption that $\sigma \phi<1$ is equivalent to assuming that competition for easy projects (i.e., projects that look good to all the firms) is intense. Because endogenizing such considerations by adding competitive forces, as in Appendix B, into our main model does not add to our results, we keep the assumption exogenous for the entire paper.
} 
affects the manager's evaluation of contracts. ${ }^{15}$ Specifically, we characterize how an imbalance between risk aversion, overconfidence, and compensation contracts can lead to a suboptimal investment policy when the manager's information is not verifiable.

Suppose that the manager is compensated with a contract $\left\{\delta_{\mathrm{M}}, \delta_{\mathrm{H}}\right\}$, where $\delta_{\mathrm{M}} \geq 0$ and $\delta_{\mathrm{H}} \geq 0$. Clearly, this contract creates an incentive for the manager to undertake risky projects if $\delta_{\mathrm{H}}$ is large relative to $\delta_{\mathrm{M}}$, as the manager then gives up large potential gains by sticking to a safe project that guarantees him a compensation of $\delta_{\mathrm{M}}$. The opposite is true when $\delta_{\mathrm{H}}$ is small relative to $\delta_{\mathrm{M}}$ : the manager might as well keep the investment policy safe in order not to risk losing $\delta_{\mathrm{M}}$ to risky projects that fail. The manager's decisions are summarized in the following lemma.

LEMMA 3: If the manager observes a positive signal $(\tilde{s}=\sigma)$, then he undertakes the project as long as

$$
\frac{\delta_{\mathrm{H}}}{\delta_{\mathrm{M}}} \geq \frac{1-\hat{\phi}_{\mathrm{U}}}{\hat{\phi}_{\mathrm{U}}(1-r)}=\frac{(1-\phi)(1-a-b)}{1-(1-\phi)(1-a-b)} \frac{1}{1-r} \equiv \hat{\kappa}_{\mathrm{U}} .
$$

If, instead, the manager observes a negative signal $(\tilde{s}=0)$, then he undertakes the project as long as

$$
\frac{\delta_{\mathrm{H}}}{\delta_{\mathrm{M}}} \geq \frac{1-\hat{\phi}_{\mathrm{D}}}{\hat{\phi}_{\mathrm{D}}(1-r)}=\frac{1-\phi(1-a-b)}{\phi(1-a-b)} \frac{1}{1-r} \equiv \hat{\kappa}_{\mathrm{D}} .
$$

It is easy to verify that $\hat{\kappa}_{\mathrm{U}}<\hat{\kappa}_{\mathrm{D}}$ : the risky project is more attractive to the manager when he observes a positive signal than when he observes a negative signal. Since $\delta_{\mathrm{H}}$ is the additional compensation received by the manager for a successful project, it can be interpreted as option or bonus compensation, and the ratio $\frac{\delta_{\mathrm{H}}}{\delta_{\mathrm{M}}}$ effectively measures the convexity of the compensation contract. Given a contract $\left\{\delta_{\mathrm{M}}, \delta_{\mathrm{H}}\right\}$, the manager follows a more conservative investment policy as his risk aversion increases: the potential utility gains associated with departures from the status quo, $(1-r) \delta_{\mathrm{H}}$, become relatively smaller than the potential utility losses, $\delta_{\mathrm{M}}$. This is why both $\hat{\kappa}_{\mathrm{U}}$ and $\hat{\kappa}_{\mathrm{D}}$ are increasing in $r$ : more convexity is required for the manager to undertake the risky project when $r$ is large.

The manager's overconfidence can make his investment policy more or less aggressive. Because $\hat{\kappa}_{U}$ is decreasing in $b$, an overconfident manager is more attracted to the risky project following a positive signal $(\tilde{s}=\sigma)$ than an otherwise identical but rational manager would be. At the same time, because $\hat{\kappa}_{\mathrm{D}}$ is increasing in $b$, an overconfident manager is more reluctant to undertake the risky project following a negative signal $(\tilde{s}=0)$ than his rational counterpart.

\footnotetext{
15 Another difference is the source of the incongruity. The friction in their model stems from the fact that managerial skills are unknown by all at the outset, creating career concerns for the manager. The friction in our model revolves around risk-sharing issues (in Sections I and II) and costly effort (in Section III).
} 


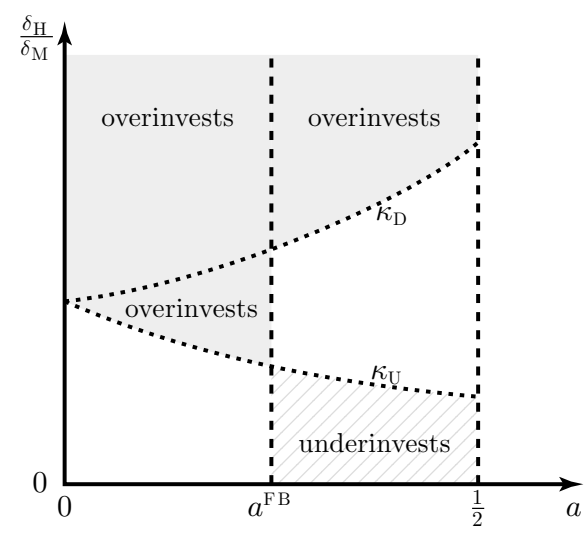

(a) Unbiased manager $(b=0)$

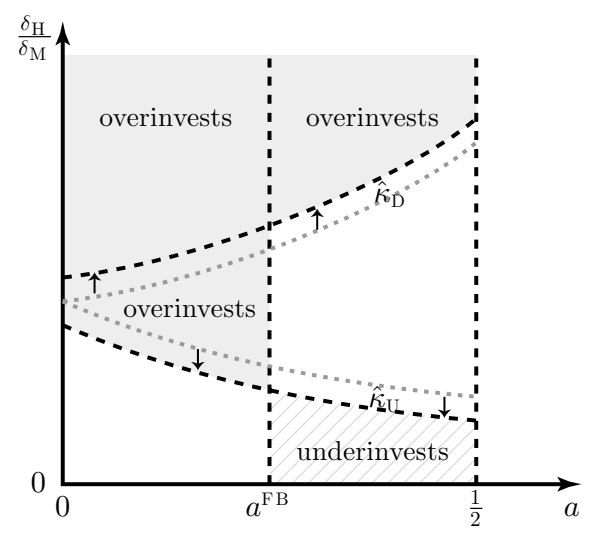

(b) Overconfident manager $(b>0)$

Figure 2. This figure shows when the manager overinvests and when he underinvests, first for an unbiased manager $(b=0$ in $(A))$ and then for an overconfident manager $(b>$ $\mathbf{0}$ in (B)). When the manager's skill is low $\left(a<a^{\mathrm{FB}}\right)$, he overinvests if his compensation ever creates an incentive for him to undertake the risky project. When the manager's skill is high ( $a$ $>a^{\mathrm{FB}}$ ), he overinvests if his compensation creates an incentive for him to undertake the project following a negative signal $(\tilde{s}=0)$, and he underinvests if his compensation creates an incentive for him to drop the risky project following a positive signal $(\tilde{s}=\sigma)$. As the manager becomes more overconfident (as $b$ increases), $\hat{\kappa}_{U}$ decreases and $\hat{\kappa}_{\mathrm{D}}$ increases.

Thus, whereas risk aversion always makes the manager more conservative, his overconfidence makes him more aggressive with positive information and more conservative with negative information.

It follows from Lemmas 2 and 3 that, relative to the firm's optimal policy, the manager overinvests when $\frac{\delta_{\mathrm{H}}}{\delta_{\mathrm{M}}}$ is too large and he underinvests when $\frac{\delta_{\mathrm{H}}}{\delta_{\mathrm{M}}}$ is too small. Figure 2 (a) illustrates this more precisely. It is straightforward to verify that the manager underinvests when he is highly risk-averse and when he receives only a small fraction of his compensation through performance-based compensation.

As can be seen from Figure 2(b), the manager's overconfidence increases the incidence of overinvestment when his skill level is low $\left(a<a^{\mathrm{FB}}\right)$, but reduces both overinvestment and underinvestment when he is highly skilled $\left(a>a^{\mathrm{FB}}\right)$. Because the overconfident manager thinks that he receives a more precise signal than he actually does, he is more inclined to undertake a risky project with imperfect information. However, too much overconfidence can be detrimental, as it can lead the manager to overinvest when he is not sufficiently skilled to create value.

In essence, overinvestment and underinvestment result from managerial compensation contracts $\left\{\delta_{\mathrm{M}}, \delta_{\mathrm{H}}\right\}$ that do not appropriately adjust to the project's characteristics or the manager's risk aversion, skill, and overconfidence. As we show in the next section, optimized compensation contracts will endogenously adjust to these quantities, eliminating both overinvestment and underinvestment. 


\section{The Firm's Problem}

We now turn to the firm's problem of choosing the contract $\left\{\delta_{\mathrm{M}}, \delta_{\mathrm{H}}\right\}$ that maximizes its value. As shown in Lemma 2 , the firm can never hope to increase its value by hiring a manager with $a \leq a^{\mathrm{FB}}$, and so we make the following assumption, which we maintain throughout the rest of the paper.

Assumption 1: The manager's skill a is such that $a>a^{\mathrm{FB}}=1-\frac{\sigma-1}{\sigma(1-\phi)}$.

Even when the manager is sufficiently skilled, his investment policy does not automatically add value: the manager must make the decision to invest in the risky project dependent on $\tilde{s}$ for any value to be created. Thus, value creation requires that the manager's investment incentives be realigned with those of the firm. From Lemma 3, incentive compatibility means that the manager's compensation contract must satisfy

$$
\hat{\kappa}_{\mathrm{U}} \leq \frac{\delta_{\mathrm{H}}}{\delta_{\mathrm{M}}} \leq \hat{\kappa}_{\mathrm{D}}
$$

As in standard principal-agent problems, we assume that the manager's opportunities outside the firm yield him an expected utility of $\bar{u}>0$. For the manager to join the firm, he must expect at least $\bar{u}$ in utility from the firm's compensation contract and the investment policy that he follows. ${ }^{16}$ Because the firm will ensure that the manager's incentive-compatibility constraint (IC) is satisfied (the manager is not worth hiring otherwise), the manager's expected utility is

$$
\begin{aligned}
\hat{\mathrm{E}}[\tilde{u}]= & \hat{\operatorname{Pr}}\{\tilde{s}=\sigma\} \hat{\operatorname{Pr}}\{\tilde{v}=\sigma \mid \tilde{s}=\sigma\}\left[\delta_{\mathrm{M}}+(1-r) \delta_{\mathrm{H}}\right]+\hat{\operatorname{Pr}}\{\tilde{s}=0\} \delta_{\mathrm{M}} \\
& =\phi \hat{\phi}_{\mathrm{U}}\left[\delta_{\mathrm{M}}+(1-r) \delta_{\mathrm{H}}\right]+(1-\phi) \delta_{\mathrm{M}},
\end{aligned}
$$

and so his participation constraint $(\mathrm{PC})$ is given by

$$
\phi \hat{\phi}_{\mathrm{U}}\left[\delta_{\mathrm{M}}+(1-r) \delta_{\mathrm{H}}\right]+(1-\phi) \delta_{\mathrm{M}} \geq \bar{u} .
$$

If we let $\tilde{\rho}$ denote the profit from the firm's investment and $\tilde{w}$ denote the compensation that the firm pays the manager, the value of the firm is $F \equiv$ $1+E[\tilde{\pi}]$, where $\tilde{\pi} \equiv \tilde{\rho}-\tilde{w}$ represents the firm's net profit. ${ }^{17}$ Thus, the firm's problem can be stated as follows:

$$
\max _{\left\{\delta_{\mathrm{M}}, \delta_{\mathrm{H}}\right\}} E[\tilde{\pi}] \quad \text { subject to (IC) and (PC). }
$$

The following proposition derives the solution to this maximization problem.

\footnotetext{
${ }^{16}$ When $\bar{u}$ is exogenously specified, it must be low enough for the firm to afford the manager's services. We assume that this is the case throughout the paper.

17 That is, $\tilde{\rho}$ is equal to $-1,0$, and $\sigma-1$ in the low, medium, and high states, respectively, while $\tilde{w}$ is $0, \delta_{\mathrm{M}}$, and $\delta_{\mathrm{M}}+\delta_{\mathrm{H}}$ in these states.
} 


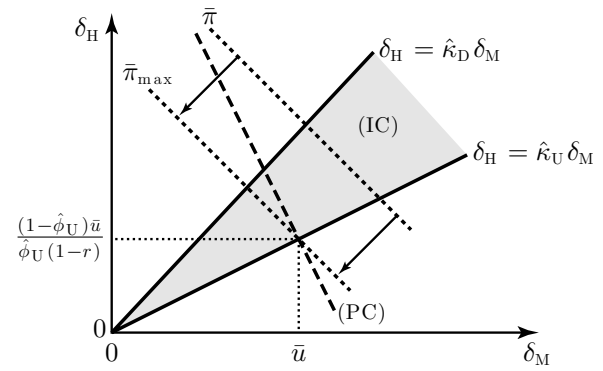

(a) $r \geq r^{*}$ or $b \leq b^{*}$

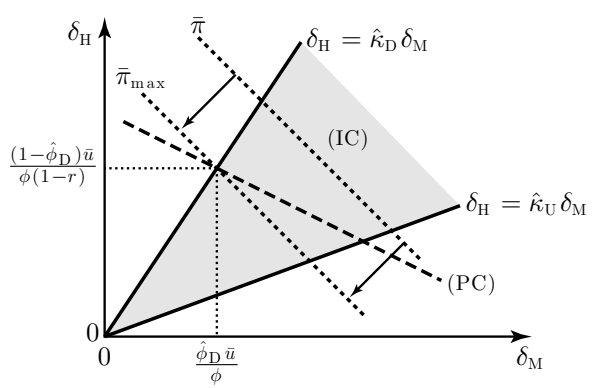

(b) $r<r^{*}$ and $b>b^{*}$

Figure 3. This figure illustrates the solution to the firm's maximization problem in (6). The shaded area represents the set of incentive-compatible contracts (IC). The dashed line is the boundary of the set of contracts that satisfy the manager's participation constraint (i.e., (PC) with an equality sign). The dotted lines are the firm's iso-profit curves. The firm picks the lowest isoprofit curve that intersects (IC) and (PC). When $r \geq r^{*}$ or $b \leq b^{*}$, where $r^{*}$ and $b^{*}$ are as defined in Proposition 1, the solution lies on the lower boundary of the (IC) region as in (a); otherwise, the solution lies on the upper boundary of the (IC) region as in (b).

PROPOSITION 1: Suppose that Assumption 1 holds. If the manager's risk aversion is sufficiently high in that

$$
r \geq \frac{1-\phi}{1-\phi+\phi \phi_{\mathrm{U}}} \equiv r^{*},
$$

or his overconfidence is sufficiently low in that

$$
b \leq \frac{r \phi_{\mathrm{U}}\left(1-\phi+\phi \phi_{\mathrm{U}}\right)}{(1-\phi)\left[1-\phi-r\left(1-\phi+\phi \phi_{\mathrm{U}}\right)\right]} \equiv b^{*},
$$

then the optimal contract is given by

$$
\delta_{\mathrm{M}}=\bar{u}, \quad \delta_{\mathrm{H}}=\frac{\left(1-\hat{\phi}_{\mathrm{U}}\right) \bar{u}}{\hat{\phi}_{\mathrm{U}}(1-r)} .
$$

If the manager's risk aversion is low (i.e., $r<r^{*}$ ) and his overconfidence is high (i.e., $b>b^{*}$ ), then the optimal contract is given by

$$
\delta_{\mathrm{M}}=\frac{\hat{\phi}_{\mathrm{D}} \bar{u}}{\phi}, \quad \delta_{\mathrm{H}}=\frac{\left(1-\hat{\phi}_{\mathrm{D}}\right) \bar{u}}{\phi(1-r)} .
$$

The two graphs in Figure 3 provide some intuition for this result. In both graphs, the shaded region represents the set of contracts that satisfy the manager's IC, and the dashed line shows the set of contracts that lie on the boundary of the manager's participation constraint (i.e., (PC) with an equality sign, as the firm has nothing to gain from offering the manager a compensation contract that yields him more than his reservation utility). Under (IC), we know from Lemma 2 that the expected investment profits of the firm are 
$E[\tilde{\rho}]=\phi\left(\sigma \phi_{\mathrm{U}}-1\right)$. This quantity is unaffected by the choice of contract, as long as the contract is incentive compatible. Thus, the firm's objective is to find the cheapest compensation contract, or the lowest iso-profit curve, that intersects both (IC) and (PC). ${ }^{18}$

When the manager's risk aversion is sufficiently high $\left(r \geq r^{*}\right)$ or his overconfidence is sufficiently low $\left(b \leq b^{*}\right)$, he values the extra compensation $\delta_{\mathrm{H}}$ that he receives in the high state less than the firm does, and so his PC is steeper than the firm's iso-profit curves. As shown in Figure 3(a), the optimal contract then lies on the lower boundary of the (IC) area. When the manager is sufficiently overconfident (i.e., $b>b^{*}$ ) but not excessively risk-averse (i.e., $r<r^{*}$ ), his bias more than offsets the effect of his risk aversion on the utility he gets from $\delta_{\mathrm{H}}$. In other words, though the manager derives less utility from wealth in the high state than does the firm, he also grossly overestimates the probability of the high state occurring; thus, ex ante, he values high-state compensation more than the firm does. This makes the manager's PC flatter and, as shown in Figure 3(b), implies that the optimal compensation contract lies on the upper boundary of the (IC) set.

As the following corollary shows, the properties of the optimal compensation contract depend on whether (7) and (8) are satisfied.

COROLlary 1: Suppose that Assumption 1 holds. (i) If the manager's risk aversion is sufficiently high (i.e., $r>r^{*}$ ) or his overconfidence is sufficiently low (i.e., $\left.b<b^{*}\right)$, the optimal high-state compensation offered by the firm, $\delta_{\mathrm{H}}$, is decreasing in overconfidence, $b$, while the optimal medium-state compensation, $\delta_{\mathrm{M}}$, does not vary with $b$. (ii) If risk aversion is low (i.e., $r<r^{*}$ ) and overconfidence high (i.e., $b>b^{*}$ ), the optimal high-state compensation, $\delta_{\mathrm{H}}$, is increasing in overconfidence, $b$, while the optimal medium-state compensation, $\delta_{\mathrm{M}}$, is decreasing in $b$.

As the manager goes from being rational to slightly overconfident (as $b$ increases from zero), it becomes cheaper for the firm to motivate him to undertake the risky project following a positive signal $(\tilde{s}=\sigma)$. This is because the manager thinks that his information is more risk-reducing than it really is, and so he requires a smaller $\delta_{\mathrm{H}}$ to undertake the project. When $b$ exceeds $b^{*}$, however, the manager values $\delta_{\mathrm{H}}$ more than the firm does (provided that $r<r^{*}$ ), and so it is cheaper for the firm to impose risk on the manager through more high-state compensation.

Note that increasing the manager's overconfidence more than offsets the effect of increasing his risk aversion. Specifically, even if two managers trade off high-state and medium-state compensation the same way at the outset (before they receive their signal about $\tilde{v}$ ), the firm always prefers (i.e., is more valuable if it hires) the manager with the higher risk aversion and overconfidence. To see this, one can increase both $b$ and $r$ in such a way that the slope of the manager's

\footnotetext{
${ }^{18}$ More precisely, the contract that maximizes the firm's value must minimize the expected compensation of the manager, which, under (IC), is given by $E[\tilde{w}]=\operatorname{Pr}\{\tilde{s}=\sigma\} \operatorname{Pr}\{\tilde{v}=\sigma \mid \tilde{s}=$ $\sigma\}\left(\delta_{\mathrm{M}}+\delta_{\mathrm{H}}\right)+\operatorname{Pr}\{\tilde{s}=0\} \delta_{\mathrm{M}}=\phi \phi_{\mathrm{U}}\left(\delta_{\mathrm{M}}+\delta_{\mathrm{H}}\right)+(1-\phi) \delta_{\mathrm{M}}$.
} 
iso-utility curves stays constant. ${ }^{19}$ Despite the fact that these managers have the same preferences over state-contingent compensation at the outset, the set of incentive-compatible contracts of the manager with the higher risk aversion and overconfidence can be shown to be strictly larger than that of the other manager. $^{20}$

This further implies that, although the manager's iso-utility curves are parallel to the firm's iso-profit curves when his overconfidence is $b=b^{*}$, such a manager is preferred to a rational, risk-neutral manager by the firm. These two types of managers value state-contingent claims the same way prior to observing $\tilde{s}$, but the overconfident, risk-averse manager (with $b=b^{*}$ ) does not use his information like a rational, risk-neutral manager (with $b=0$ ) would at the investment stage. In short, and as Goel and Thakor (2008) point out in a related context, although overconfidence helps reduce the effects of the manager's risk aversion, it is not equivalent to an actual reduction in risk aversion.

The firm takes advantage of the fact that the manager overestimates his skill. As the following proposition shows, this benefit is monotonic in the manager's overconfidence and is affected by the firm's and the manager's characteristics.

Proposition 2: Suppose that Assumption 1 holds. (i) The value of the firm is increasing in the manager's overconfidence (b). (ii) Keeping the ex ante expected payoff of the project $(\sigma \phi)$ fixed, hiring an overconfident manager is more beneficial to the firm when the upside potential of the project $(\sigma)$ is large, the unconditional probability of the project being successful $(\phi)$ is small, the manager's risk aversion ( $r$ ) is large, and the manager's true ability $(a)$ is small.

The overconfident manager requires fewer compensation incentives to follow a risky investment policy and makes his decision to join the firm based on biased beliefs. Both lead to a reduction in the firm's compensation expense and to an increase in firm value. Both also have a negative impact on the manager's welfare (i.e., $E[\tilde{u}]$ is monotonically decreasing in $b$ ), although the manager does not realize this ex ante.

As the second part of Proposition 2 shows, the presence of managerial overconfidence is more beneficial to firms whose projects are riskier. Specifically, among firms whose projects have the same ex ante expected payoffs, the ones that have a small chance of realizing a large payoff will tend to benefit more from hiring an overconfident manager. ${ }^{21}$ This is due to the fact that riskier projects require more incentive compensation, so force the firm to impose more risk on the manager. Because overconfidence reduces risk-sharing costs, it is especially useful for these types of projects and when the manager's risk aversion is large.

\footnotetext{
${ }^{19}$ Using (PC), this is done by increasing $b$ (and thus $\hat{\phi}_{\mathrm{U}}$ ) and $r$ in such a way that $-\frac{1}{1-r}\left(1+\frac{1-\phi}{\phi \hat{\phi}_{\mathrm{U}}}\right)$ stays constant.

${ }^{20}$ Specifically, one can show that $\hat{\kappa}_{\mathrm{U}}$ and $\hat{\kappa}_{\mathrm{D}}$, as derived in Lemma 3, are, respectively, smaller and larger as a result of the aforementioned increases in $b$ and $r$.

${ }^{21}$ Ex ante, these projects also have a larger variance, as $\operatorname{Var}(\tilde{v})=\phi(\sigma-\sigma \phi)^{2}+(1-\phi)(0-$ $\sigma \phi)^{2}=\sigma^{2} \phi(1-\phi)=\sigma \phi[\sigma(1-\phi)]$, which, keeping $\sigma \phi$ constant, is larger for large $\sigma$ and small $\phi$.
} 
The second part of Proposition 2 also shows that overconfidence is less useful when the manager is highly skilled. If, as in the model of Gabaix and Landier (2008), more skilled managers tend to get matched with larger firms, then our model also predicts that managerial overconfidence will be stronger in smaller firms. In sum, Proposition 2 leads to the following prediction.

PREDICTION 1: Managerial overconfidence and the sensitivity of compensation to firm performance is predicted to be stronger in firms whose projects are riskier (in the sense that they have a high failure rate but large upside potential) and in small firms.

This prediction is consistent with the work of Mehran (1995), Aggarwal and Samwick (1999), and Palia (2001), who document a positive relationship between incentive compensation and various proxies for risky growth opportunities, including $\mathrm{R} \& \mathrm{D}$, market-to-book ratio, and the intangibility of assets. It is also consistent with the finding that the pay-performance sensitivity of CEOs in small firms exceeds that of CEOs in large firms, as documented by Schaefer (1998) and Baker and Hall (2004). Also in line with Prediction 1. is Campbell et al.'s (2010) finding that excessive CEO overconfidence is associated with more frequent failure and forced turnover. Finally, note that, even though smaller firms are more likely to be managed by founding entrepreneurs (who tend to be overconfident), Prediction 1 should apply even after setting aside founders.

\section{The Role of Labor Markets}

In the previous section, the manager joins the firm if he expects more utility from the firm than from an exogenously fixed set of outside opportunities, as in the principal-agent models of Ross (1973) and Holmström (1979). All economic surplus is captured by the firm. Moreover, as in the work of Goel and Thakor (2008), Adrian and Westerfield (2009), and Palomino and Sadrieh (2011), the firm takes advantage of the manager's bias and thus is more valuable as his overconfidence rises.

In this section, we introduce a labor market that serves to endogenize the manager's reservation utility. Firms bid for the manager's services using compensation contracts, and the utility that a manager expects from one firm's bid becomes the manager's outside opportunity that another firm must beat to attract him. The manager's best outside option is hence endogenous and is affected by his personal attributes, including his overconfidence. As we show, the manager derives all (some) of the economic surplus when homogeneous (heterogeneous) firms compete for his services, and his overconfidence then affects his own welfare, sometimes positively so. Because extreme managerial risk aversion always leads the manager to prefer the safest form of compensation, we make the following assumption from here on.

AsSUMPTION 2: The manager's risk aversion $r$ is such that $r<r^{*}=\frac{1-\phi}{1-\phi+\phi \phi_{\mathrm{U}}}$. 


\section{A. Competition between Homogeneous Firms}

As explained in the discussion following Proposition 2, the optimal contract of Proposition 1 makes the firm more valuable and the manager worse off as $b$ increases. Clearly, this outcome is not possible if many firms compete for the manager's services. From these firms' perspective, the manager's skills represent a valuable asset rendered cheap by his overconfidence. Any firm offering a compensation package that effectively transfers surplus from the manager to the firm will be overbid by some other firm. In an effort to attract the manager, these firms are willing to offer a more generous compensation contract. As we show in this section, this competition for the manager can make his overconfidence welfare-improving.

Let us assume that two firms are competing to hire one manager, who chooses which firm to work for based on the utility he expects to receive from the compensation contracts they offer (he picks a firm randomly if his expected utility is the same for both). For now, we assume that these two firms are identical to the one firm that we have modeled so far. For simplicity, we also assume that managerial skills are a scarce resource: the firm that fails to hire this one manager must operate with an unskilled manager $(a=0)$ or without one altogether. The firm without the skilled manager cannot generate any value from risky projects, and thus is worth its initial cash position of one dollar.

As long as the manager is given an incentive-compatible contract, we know from Lemma 2 that he increases the firm's expected end-of-period value by $\phi\left(\sigma \phi_{\mathrm{U}}-1\right)$. Because the two firms compete away all of the available surplus in order to hire the manager, the compensation contract $\left\{\delta_{\mathrm{M}}, \delta_{\mathrm{H}}\right\}$ that the manager ends up accepting in equilibrium costs exactly the same amount. That is, in equilibrium, both firms are worth one dollar regardless of whether they are successful in hiring the manager, and the compensation contract satisfies a zero-profit condition (ZP). The equilibrium contract must also maximize the manager's expected utility, calculated according to his biased beliefs. This contract must therefore solve the following problem:

$$
\begin{gathered}
\max _{\left\{\delta_{\mathrm{M}}, \delta_{\mathrm{H}}\right\}} \hat{\mathrm{E}}[\tilde{u}] \quad \text { subject to (IC) and } \\
E[\tilde{\rho}]=\phi\left(\sigma \phi_{\mathrm{U}}-1\right)=\phi \phi_{\mathrm{U}}\left(\delta_{\mathrm{M}}+\delta_{\mathrm{H}}\right)+(1-\phi) \delta_{\mathrm{M}}=E[\tilde{w}] .
\end{gathered}
$$

Because the manager chooses which firm to work for, firms make themselves attractive by offering competitive contracts that appeal to him. This, as we show below, can make the manager vulnerable to his overconfidence, but can also strengthen his bargaining power. The following proposition derives the contract that the manager receives in equilibrium.

Proposition 3: Suppose that Assumptions 1 and 2 hold. If the manager's overconfidence is sufficiently small (i.e., if $b \leq b^{*}$, where $b^{*}$ is as defined in (8)), then 


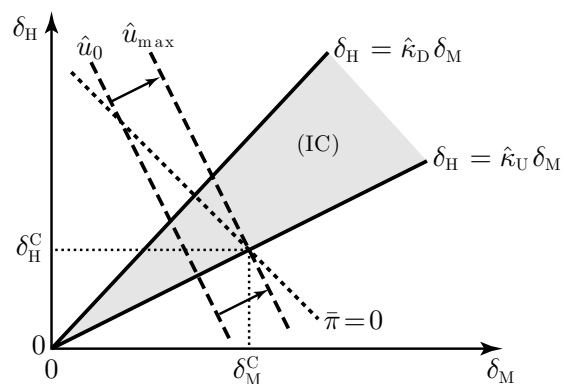

(a) $b<b^{*}$

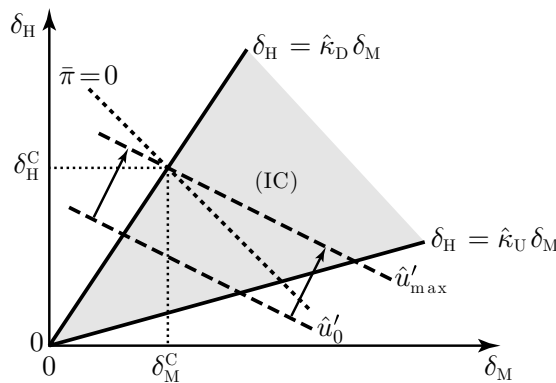

(b) $b>b^{*}$

Figure 4. This figure illustrates the solution to the competitive equilibrium for the manager's services. The shaded area represents the set of incentive-compatible contracts (IC). The dotted line labeled $\bar{\pi}=0$ represents the set of contracts that leave the firms with zero expected profits under (IC). The dashed lines are the manager's iso-utility curves (calculated according to the manager's biased beliefs). The competitive equilibrium is the highest iso-utility curve (labeled $\left.\hat{u}_{\max }\right)$ that intersects both sets. When $b<b^{*}$, where $b^{*}$ is as defined in Proposition 1 , the solution lies on the lower boundary of the (IC) region as in (a); otherwise, the solution lies on the upper boundary of the (IC) region as in (b).

the equilibrium contract is given by

$$
\delta_{\mathrm{M}}=\frac{\phi\left(\sigma \phi_{\mathrm{U}}-1\right)}{1-\phi+\phi \phi_{\mathrm{U}}\left(1+\hat{\kappa}_{\mathrm{U}}\right)}, \quad \delta_{\mathrm{H}}=\hat{\kappa}_{\mathrm{U}} \delta_{\mathrm{M}} .
$$

If the manager's overconfidence is sufficiently large (i.e., if $b>b^{*}$ ), then the equilibrium contract is given by

$$
\delta_{\mathrm{M}}=\frac{\phi\left(\sigma \phi_{\mathrm{U}}-1\right)}{1-\phi+\phi \phi_{\mathrm{U}}\left(1+\hat{\kappa}_{\mathrm{D}}\right)}, \quad \delta_{\mathrm{H}}=\hat{\kappa}_{\mathrm{D}} \delta_{\mathrm{M}}
$$

As in Proposition 1, the form and properties of the equilibrium compensation contract depend on whether the manager is mildly or highly overconfident. This is illustrated in Figure 4 . When the manager is mildly overconfident as in Figure 4(a), his risk aversion makes him prefer contracts along the lower boundary of the incentive-compatible set. However, when his overconfidence $b$ rises above $b^{*}$, the manager is more attracted by high-state compensation, which he thinks he can generate with high probability. In an effort to attract the manager, the firms are content to satisfy the manager's preference for performance-based compensation, and the resulting equilibrium contract lies on the upper boundary of the incentive-compatible set, as in Figure 4(b). As the following result shows, the extent of the manager's overconfidence has an important impact on the properties of his compensation contract and in turn on his welfare.

Proposition 4: Suppose that Assumptions 1 and 2 hold. (i) When the manager's overconfidence is sufficiently small (i.e., $b<b^{*}$ ), an increase in $b$ results in $a$ larger $\delta_{\mathrm{M}}$, a smaller $\delta_{\mathrm{H}}$, and more expected utility for the manager. (ii) When 
the manager's overconfidence is sufficiently large (i.e., $b>b^{*}$ ), an increase in $b$ results in a smaller $\delta_{\mathrm{M}}$, a larger $\delta_{\mathrm{H}}$, and less expected utility for the manager.

When $b<b^{*}$, the overconfident manager receives a less convex compensation than an otherwise identical but rational manager. This result is similar to that of Section I.D, but it obtains for a different reason. In this case, it is the manager who effectively chooses his own compensation from a set of contracts that leave the two firms with no net increase in value. His overconfidence therefore commits him to a compensation contract with a higher base salary and less performance-related compensation. This is due to the fact that the manager thinks that he can generate the extra compensation that the high state offers with higher probability than he really can. As a result, the firms seek to attract him with a higher base salary, which, because of the manager's risk aversion, he values more and is cheaper to the firms. Inadvertently, the manager's bias increases the surplus that the firms can use to bid for his services. The resulting compensation package is larger and safer, and it makes the manager better off.

Another interpretation of Propositions 3 and 4 is in terms of salary negotiations. The compensation contract specified in (12) with some $b>0$ does not appeal to a rational manager but does to an overconfident manager whose overconfidence is $b$. That is, the manager's overconfidence gives credibility to his threat to accept this contract when it is offered by a competing firm. For him, the contract provides sufficient incentives to make it attractive. When $b>b^{*}$, however, the credibility of his threat backfires, as he is willing to accept the steeper contract in (13) because the larger reliance on performance-based compensation is particularly attractive to him. In this case, he ends up negotiating a contract that makes him worse off.

Proposition 1 derives the equilibrium compensation contract when the manager's outside opportunities are fixed. In this case, the firm has all the bargaining power and captures all the economic surplus. In contrast, Proposition 3 derives the equilibrium compensation contract when homogeneous firms bid for the manager's services. In this second case, the manager has all the bargaining power and hence ends up with the entire surplus. In reality, bargaining power and economic surplus are often shared, to varying degrees, by firms and managers. Figure 4 enables us to visualize the shift in optimal contracts as competition travels the continuum from no competition between firms to intense competition. Specifically, if we let the dashed line labeled $\hat{u}_{0}$ represent the boundary for the set of contracts that the manager is willing to accept (i.e., his PC in Section I), the equilibrium contract moves from this line to that denoted by $\hat{u}_{\max }$ as competition in the labor markets intensifies. When the manager's overconfidence is small, the manager's compensation moves along the contract line defined by $\delta_{\mathrm{H}}=\hat{\kappa}_{\mathrm{U}} \delta_{\mathrm{M}}$. However, when $b$ is large, the manager's compensation moves along $\delta_{\mathrm{H}}=\hat{\kappa}_{\mathrm{D}} \delta_{\mathrm{M}}$ as competition for his services increases.

PREDICTION 2: As competition for skilled managerial labor intensifies, the performance-based compensation of managers with low overconfidence increases less than that of managers with high overconfidence. 
Regressions of managers' option compensation on a variable that interacts overconfidence and a measure of labor competition should shed light on the validity of Prediction 2 . The key to such tests is to find a proxy for the degree of competition in labor markets. Possible measures include the unemployment rate or the state of the economy. For example, MacLeod and Parent (1999) find that firms are more likely to include performance bonuses in compensation contracts when the unemployment rate is low, and interpret this as evidence that the use of incentive compensation increases as labor conditions tighten. Similarly, we would expect the extent of bonus and option compensation to increase more for highly overconfident managers as the unemployment rate decreases or as the business cycle goes from a recession to an expansion.

Competition by firms for the same manager is also more likely to take place when the manager's skills are portable from one industry to the next. ${ }^{22}$ A position that requires industry-specific skills is less likely to force a firm to compete for an agent with a firm from another industry. In a study on the market for corporate executives, Frydman (2005) documents that the increase in the generality of managerial skills has led to a rise in CEO pay between 1936 and 2003. Likewise, Murphy and Zábojník (2007) show that more transferable human capital expands CEOs' outside options. We would therefore expect more performance-based compensation to be associated with positions that require general skills. When the manager's skills are industry-specific, a test of Prediction 2 could use fluctuations in the number of firms within an industry as a time-series proxy for labor market competition.

We finish this section by noting that $\delta_{\mathrm{M}}$, in both (12) and (13), depends on the manager's skill $(a)$ not just through its dependence on the manager's perceived skill $(a+b)$. Indeed, the economic surplus that the two firms compete away depends not only on $a+b$ through the compensation contract they offer the overconfident manager, but also on the manager's actual skill and the profits that this skill effectively generates. Therefore, technically speaking, the manager could learn something about his own bias through the equilibrium contract derived in Proposition 3. We abstract from such a possibility and keep our underlying assumption that the manager and firms agree to disagree as to whether the manager is more highly skilled or overconfident. This can be justified on two grounds.

First, the characteristics of managers, projects, and firms vary on many dimensions. This means that, in a more general setting, the manager would use the equilibrium compensation contract to update his beliefs about a large array of unknown quantities (e.g., his own skill and overconfidence, the project's cost, risk, and time to maturity, and the firm's assets in place and growth prospects). As such, the manager's beliefs about his own skill and overconfidence are unlikely to change much, and the effects of his bias will be largely unaffected by contracting. For example, in our model, one could assume that the manager

\footnotetext{
${ }^{22}$ Murphy and Zábojník (2007) develop a model and present empirical evidence showing that managers with more general skills tend to be hired from outside the firm.
} 
does not know the payoff $\sigma$ of a successful project; he only knows its distribution. The contract in (12) is then higher than the manager initially expects, and this leads him to revise his expectations about $\sigma$ upwards (and the opposite is true for the contract in (13)).

Second, and perhaps more importantly, we envision a manager who is aware of the beliefs of others and continues to think that he has more skill than others believe him to have. Our assumption is consistent with evidence that overconfidence is both pervasive and persistent, especially for corporate executives (e.g., Ben-David et al. (2010)). DeBondt and Thaler (1995, p. 389) describe overconfidence as "[p]erhaps the most robust finding in the psychology of judgment." Fischhoff (1982) finds that overconfidence is resistant to many forms of debiasing. Taylor and Brown (1988) argue that moderate degrees of overconfidence and other self-serving biases are consistent with good mental health. Furthermore, several behavioral biases including self-attribution bias, confirmation bias, hindsight bias, and the illusion of control may serve to reinforce a person's overconfidence.

\section{B. Competition between Heterogeneous Firms}

Suppose now that the two firms competing for the manager's services are not identical. In particular, let us assume that firm $\mathrm{G}$, a growth firm, has more upside potential and smaller assets in place than firm $\mathrm{V}$, a value firm. To capture this, we assume that the two firms are as described in Section I, except that the payoff of firm G's project, $\sigma_{\mathrm{G}}$, is assumed to be greater than that of firm $\mathrm{V}$, $\sigma_{\mathrm{V}}$, and we assume that firm $\mathrm{V}$ starts with $A_{\mathrm{V}}>1$ in cash, as opposed to just one dollar for firm G. ${ }^{23}$ We keep assuming that the manager's skill is valuable to both firms, that is, (1) and (2) still apply for both firms. In this sense, the manager's skill is generic and not specific to either type of firm.

It is easy to adapt Lemma 2 to account for $A_{\mathrm{V}}>1$ and verify that the firstbest value of each firm is $F_{\mathrm{G}}^{\mathrm{FB}}=1+\phi\left(\sigma_{\mathrm{G}} \phi_{\mathrm{U}}-1\right)$ and $F_{\mathrm{V}}^{\mathrm{FB}}=A_{\mathrm{V}}+\phi\left(\sigma_{\mathrm{V}} \phi_{\mathrm{U}}-1\right)$, respectively. Thus, as $A_{\mathrm{V}}$ increases, more of firm V's value comes from its assets in place and less from its growth opportunities. In fact, because the second term in these expressions represents the growth opportunities of each firm, we can think of $\frac{F_{G}^{\mathrm{FB}}}{1}=1+\phi\left(\sigma_{G} \phi_{\mathrm{U}}-1\right)$ and $\frac{F_{V}^{\mathrm{FB}}}{A_{V}}=1+\frac{\phi\left(\sigma_{V} \phi_{\mathrm{U}}-1\right)}{A_{V}}$ as the market-to-book ratios of these firms. Clearly, because $A_{\mathrm{V}}>1$ and $\sigma_{\mathrm{V}}<\sigma_{\mathrm{G}}$, the market-to-book ratio of firm $\mathrm{V}$ is smaller than that of firm $\mathrm{G}$.

The value firm's risky project still requires an initial investment of one dollar. Thus, the assumption that $A_{\mathrm{V}}>1$ implies that this firm is left with $A_{\mathrm{V}}-1$ after the investment is made, and so it is able to offer the manager some compensation in the low state. That is, it can set $\delta_{\mathrm{L}}$ to values between zero and $A_{\mathrm{V}}-1$. Without competition for labor, this firm would find it optimal to satisfy as much of the rational manager's reservation utility as possible through

\footnotetext{
${ }^{23}$ If the value firm invests one dollar in the risky project, it ends the period with $A_{\mathrm{V}}-1$ or $A_{\mathrm{V}}-1+\sigma_{\mathrm{V}}$; otherwise, the value firm still has $A_{\mathrm{V}}$ at the end of the period. These define the three states over which contracts are defined for this firm.
} 
$\delta_{\mathrm{L}}$, since this optimally insures the manager without distorting his incentives (as shown in the proof of Proposition 5 below). This is not the case when the manager is highly overconfident; it is cheaper for the firm to offer the highly overconfident manager performance-based compensation that he overvalues.

As the following proposition shows, the growth firm, with its larger highstate cash flows, is better equipped to offer highly convex compensation and ends up hiring managers with a large $b$ when it competes with a value firm for their services. To simplify the analysis, we assume that the value firm can afford to fully insure the agent against compensation risk, which can be shown to require that $A_{\mathrm{V}}-1 \geq \phi\left(\sigma_{\mathrm{V}} \phi_{\mathrm{U}}-1\right)$.

Proposition 5: Suppose that Assumptions 1 and 2 hold. (i) There exists a $b^{* *}$ $\in\left(0, b^{*}\right)$, where $b^{* *}$ is derived in Appendix $A$ and $b^{*}$ is as defined in (8), such that if the manager's overconfidence is low, that is, if $b \leq b^{* *}$, then the value firm attracts the manager with the following contract:

$$
\delta_{\mathrm{L}}=\frac{1-\phi+\sigma_{G} \phi \phi_{\mathrm{U}}}{1-\phi+\phi \phi_{\mathrm{U}}\left(1+\hat{\kappa}_{\mathrm{U}}\right)}, \quad \delta_{\mathrm{M}}=\delta_{\mathrm{H}}=0 .
$$

(ii) If the manager's overconfidence is moderate, that is, if $b^{* *}<b \leq b^{*}$, then the growth firm attracts the manager with a contract that has $\delta_{\mathrm{L}}=0$ and $\left\{\delta_{\mathrm{M}}, \delta_{\mathrm{H}}\right\}$ as derived in (12) with $\sigma$ set equal to $\sigma_{\mathrm{V}}$.

(iii) If the manager's overconfidence is high, that is, if $b>b^{*}$, then the growth firm attracts the manager with a contract that has $\delta_{\mathrm{L}}=0$ and $\left\{\delta_{\mathrm{M}}, \delta_{\mathrm{H}}\right\}$ as derived in (13) with $\sigma$ set equal to $\sigma_{\mathrm{V}}$.

The value firm can provide the manager with more insurance than the growth firm when setting his compensation contract. At the same time, however, the value firm cannot offer him as much high-state compensation as the growth firm. Thus, when the manager's overconfidence is low $\left(b \leq b^{* *}\right)$, he prefers working for the value firm, which attracts him with a contract that provides full insurance (i.e, with $\delta_{\mathrm{L}}>0$ and $\delta_{\mathrm{M}}=\delta_{\mathrm{H}}=0$ ). As the manager's overconfidence increases, he is more attracted to high-state compensation, since he overestimates the likelihood that he will receive this compensation. Because the growth firm has greater ability to offer the manager such compensation (i.e., because $\sigma_{\mathrm{G}}>\sigma_{\mathrm{V}}$ ), it becomes easier for the growth firm to attract him.

As the proof of Proposition 5 shows, when the firms competing to hire the manager differ in terms of their current assets and future prospects, only one firm's net profits are driven to zero in equilibrium. Indeed, the firm that attracts the manager sets its compensation just above the level at which the other firm realizes zero net profits. The firm without the manager is then worth its initial cash value, and the other realizes some of the economic surplus that the manager's presence creates. The following corollary characterizes more precisely the effect of the manager's overconfidence on how this surplus is split between the manager and the firm that hires him.

COROLlary 2: (i) When the manager's overconfidence is low (i.e., $b<b^{* *}$ ), an increase in $b$ reduces the value of the value firm and makes the manager better 
off. (ii) When the manager's overconfidence is moderate (i.e., $b^{* *}<b<b^{*}$ ), an increase in $b$ reduces the value of the growth firm and makes the manager better off. (iii) When the manager's overconfidence is high (i.e., $b>b^{*}$ ), an increase in $b$ increases the value of the growth firm and makes the manager worse off.

As before, the manager's overconfidence has a nonmonotonic effect on the economic surplus that his presence creates and on how this surplus is divided. When two heterogeneous firms compete to hire a manager, only the riskier firm can ever profit from his overconfidence. The value firm can only attract managers with low overconfidence (i.e., $b<b^{* *}$ ). For such levels of overconfidence, the manager's threat to leave for the competing firm is credible, and so an increase in $b$ effectively gives the manager more bargaining power vis-à-vis the value firm. This can be seen from (14): $\delta_{\mathrm{L}}$ is increasing in $b$ (since $\hat{\kappa}_{\mathrm{U}}$ is decreasing in $b$ ). As $b$ increases, the prospect of working for the growth firm becomes more attractive to the manager, and thus the value firm must provide him a larger salary to retain his services.

Although the growth firm can use high-state compensation to make its contracts more attractive to the manager than those of the value firm, it is still the case that managers who are not excessively overconfident (i.e., $b^{* *}<b<b^{*}$ ) benefit from overconfidence. The reason is the same as before: their threat to accept the competitor's offer is rendered more credible by their overconfidence. When the manager's overconfidence is excessive (i.e., $b>b^{*}$ ), however, the growth firm can easily attract the manager to its ranks by offering a compensation contract that is heavily tilted toward good outcomes.

Corollary 2 leads to the following prediction about the likely destination of overconfident managers and the terms of their employment.

PREDICTION 3: When heterogeneous firms compete to hire managers, overconfident managers are more likely to be attracted by the highly performancesensitive compensation contracts offered by risky, undiversified, growth firms than by the flatter contracts offered by safe, well-diversified, value firms.

A recent empirical study by Graham et al. (2009) is consistent with this prediction. Using height as a proxy for overconfidence, they find that CEOs who are younger and more confident are more likely to run growth companies. The same authors also find that these CEOs are less likely to be paid via a fixed salary than via performance-related compensation.

Although our model is static, it is easy to see from Proposition 5 and Corollary 2 how a change in the composition of firms in the economy will affect the flow of skilled agents. An increase in the growth prospects of a segment of the economy's firms is likely to lead overconfident managers to move to growing industries and to accept compensation terms that are highly sensitive to firm performance. One might test this last prediction, therefore, by looking at industries that have experienced increases in growth prospects. For example, industries whose market-to-book and price-earnings ratios have recently increased more than those of other industries will become relatively more attractive to overconfident managers. We would expect more overconfident managers 
to be attracted by the option packages offered by firms in these industries. This should lead to a positive relationship between the dispersion of marketto-book ratios (and price-earnings ratios) across firms and the dispersion of compensation convexity across their managers.

\section{Costly Effort}

Up to this point, we have assumed that the only agency cost present in the relationship between the firm's manager and its owners is due to the manager's risk aversion. In this context, compensation contracts only serve to realign the manager's risk-taking incentives with those of the shareholders. In particular, although we have assumed so far that the information $\tilde{s}$ that the manager receives about $\tilde{v}$ is free, it is likely that the acquisition of this information requires the manager to exert effort that is costly to him and unobservable to the firm. In this section, we add this second source of agency cost to our model. $^{24}$

Let us assume that the (additive) utility cost of this effort is $c>0$ for the manager. With this cost, the manager must now weigh the benefit of acquiring a signal about $\tilde{v}$ against the cost of doing so. Since the manager creates firm value only when he gathers and uses $\tilde{s}$ to make his capital budgeting decisions, the firm's compensation contract must motivate the manager to gather information and, as before, to use it in a value-increasing manner.

Intuitively, for any $\delta_{\mathrm{M}}$, the firm must set $\delta_{\mathrm{H}}$ to a sufficiently large value to motivate the manager to exert effort to acquire information and make informed investment decisions instead of dropping the risky project at the outset without any information. Similarly, for any $\delta_{\mathrm{H}}$, the firm must set $\delta_{\mathrm{M}}$ to a sufficiently large value to motivate the manager to exert effort to acquire information and make informed investment decisions instead of undertaking the risky project at the outset without any information.

In this context, the firm is more likely to hire a manager who overestimates the impact that he can have on the firm, as this commits him to exert effort. The overconfident manager overestimates the value of his information, and so is less reluctant to "invest some utility" into gathering it. In some cases, the firm is not interested in hiring the manager when he is rational, as no (IC) contract generates positive profits for the firm. However, the firm may be interested in hiring an otherwise identical but sufficiently overconfident manager, since it is possible to realign his incentives profitably.

It is important to note that this result holds even when the manager is riskneutral (i.e., even when $r=0$ ). This role of overconfidence has nothing to do with the manager's risk aversion. Instead, it is the commitment value of overconfidence that creates potential benefits for both the firm and the manager. When the manager is rational, the compensation convexity required to make him prefer gathering information to dropping (undertaking) the project without

\footnotetext{
${ }^{24}$ In the interest of parsimony and readability, all of this section's formal mathematical results and proofs have been moved to Appendix C.
} 
information is so large (small) that he prefers to always undertake (drop) the project without any information. Profitable realignment of the overconfident manager is possible, however, as such a manager overestimates the value of his information.

While our model assumes that the firm is unable to monitor the manager's effort, it is straightforward to make a noisy signal about managerial effort available to the firm. The potential for overconfidence to commit a manager to effort is then particularly valuable when effort comes at a great cost to the manager and when effort is difficult to measure or monitor. This leads to our last prediction.

PREDICTION 4: Overconfident managers are more likely to be employed in jobs that are difficult and require great effort, and in jobs where monitoring is costly or difficult.

The availability of public information that is correlated with the unobservable decisions of the manager is likely to make monitoring easier and cheaper. When such information is lacking, we expect managerial overconfidence to become a more important component of the firm's effort to reduce agency costs. For example, we expect the young private firms funded by venture capitalists to be headed by overconfident entrepreneurs. Not only is the monitoring of entrepreneurs difficult, but the required effort is often great. In fact, to the extent that overconfidence is related to how resolute a manager is in moving ahead with new projects, this prediction is consistent with the work of Kaplan et al. (2008), who find that individuals' execution-related skills (like aggressiveness, persistence, and being proactive) tend to be associated with their success as CEOs of firms funded by private equity investors.

Similarly, the contribution of a CEO to the success of a firm with long-term irreversible projects is likely more difficult to assess than the contribution of a CEO to the success of a firm with short-term projects that offer a quick determination of success. On average, therefore, we should expect the top management of firms that are relatively more engaged in research and development to exhibit more overconfidence. If such managers are attracted by performance-sensitive compensation, we should also find, as Yermack (1995) does, that firms include stock options in the compensation of their CEO when monitoring is difficult.

\section{Conclusion}

There are many reasons to expect CEOs and other top managers to be overconfident. Not only is overconfidence prevalent in the population, but it is prevalent among experts. ${ }^{25}$ Those who are positively biased about their management abilities are more likely to pursue careers as managers. Risk-taking

${ }^{25}$ Clinical psychologists (Oskamp (1965)), physicians and nurses (Christensen-Szalanski and Bushyhead (1981), Baumann, Deber, and Thompson (1991)), investment bankers (Staël von Holstein (1972)), engineers (Kidd (1970)), entrepreneurs (Cooper, Woo, and Dunkelberg (1988)), lawyers (Wagenaar and Keren (1986)), negotiators (Neale and Bazerman (1990)), and 
induced by overconfidence may, in a tournament-type setting, result in promotions (Goel and Thakor (2008)). Moreover, successful CEOs may attribute too much of their success to their own abilities rather than other factors and thus become increasingly overconfident (Daniel, Hirshleifer, and Subrahmanyam (1998), Gervais and Odean (2001)).

While CEOs are likely to be overconfident, the normative advice provided by academic finance to those who wish to align the decisions of managers with the desires of shareholders largely ignores this trait (e.g., Barnea, Haugen, and Senbet (1985), Murphy (1999), Hall and Murphy (2003), Hall (2003), Edmans and Gabaix (2009)). To mitigate agency concerns, corporate boards are advised to offer CEOs compensation packages that are sensitive to firm performance (e.g., salary plus stocks and options) without any discussion of how CEO overconfidence may affect the need for such compensation. At the same time, most existing models of overconfident agents ignore the possibility that the principal provides them with compensation contracts that correct their decision biases. That is, managerial biases tend to be studied independently from incentives.

In this paper, we study the interaction of managerial overconfidence and compensation in the context of a firm's investment policy. To do so, we develop a simple capital budgeting problem in which a manager, using his information about the prospects of a risky project, must decide whether his firm should undertake the project or drop it in favor of a safer investment alternative. Our model shows that a manager's overconfidence creates two potential sources of value for him and the firm. First, the manager's overconfidence implicitly commits him to follow an optimal risky investment policy with a flatter compensation schedule. This is valuable when risk-taking incentives come with suboptimal risk-sharing arrangements between firms and risk-averse managers. Second, the manager's overconfidence commits him to exert effort to gather information that improves the success rate and value of the firm's investment policy. As we show, the associated benefits can accrue to the firm, the manager, or both, depending on the extent of competition in labor markets and the size of the manager's bias.

More generally, our model shows that it is the interaction of contractual incentives with the manager's attributes, including his behavioral biases, that ultimately drives the firm's decisions. In a dynamic setting that allows for changes in the manager's attributes during his career, the pace at which his compensation evolves to commensurately realign his incentives becomes critical. The possibility that contracts do not adjust sufficiently rapidly to changing attributes is documented by $\mathrm{Li}$ (2010), who shows that managers' selfattribution bias affects corporate policies. Doukas and Petmezas (2007) and Billett and Qian (2008) also find that CEOs tend to become overconfident after a successful acquisition, and, as a result, are more likely to follow it with acquisitions that negatively impact their firm's stock price. Given this 
evidence, we should expect measures of overconfidence to more strongly correlate with value-destroying investments when compensation contracts are performance-sensitive and relatively rigid. ${ }^{26}$ These dynamic interactions between overconfidence, optimal contracts, and corporate policies offer a promising avenue for future research.

\section{Appendix A: Proofs}

Proof of Lemma 1: Suppose first that the manager observes a positive signal $\tilde{s}=\sigma$. We can use Bayes's rule to calculate his posterior beliefs about $\tilde{v}$ :

$$
\begin{aligned}
\hat{\operatorname{Pr}}\{\tilde{v}=\sigma \mid \tilde{s}=\sigma\}= & \frac{\hat{\operatorname{Pr}}\{\tilde{s}=\sigma \mid \tilde{v}=\sigma\} \hat{\operatorname{Pr}}\{\tilde{v}=\sigma\}}{\hat{\operatorname{Pr}}\{\tilde{s}=\sigma\}}=\frac{\hat{\operatorname{Pr}}\{\tilde{s}=\sigma \mid \tilde{v}=\sigma\} \phi}{\phi} \\
= & \operatorname{Pr}\{\tilde{s}=\sigma \mid \tilde{v}=\sigma, \tilde{\varepsilon}=1\} \hat{\operatorname{Pr}}\{\tilde{\varepsilon}=1 \mid \tilde{v}=\sigma\} \\
& +\hat{\operatorname{Pr}}\{\tilde{s}=\sigma \mid \tilde{v}=\sigma, \tilde{\varepsilon}=0\} \operatorname{Pr}\{\tilde{\varepsilon}=0 \mid \tilde{v}=\sigma\} \\
= & 1 \cdot(a+b)+\phi(1-a-b)=\phi+(a+b)(1-\phi),
\end{aligned}
$$

as in (1). Suppose now that the manager observes a negative signal $\tilde{s}=0$. Again, we can use Bayes's rule to calculate his posterior beliefs about $\tilde{v}$ :

$$
\begin{aligned}
\hat{\operatorname{Pr}}\{\tilde{v}=\sigma \mid \tilde{s}=0\}= & \frac{\hat{\operatorname{Pr}}\{\tilde{s}=0 \mid \tilde{v}=\sigma\} \hat{\operatorname{Pr}}\{\tilde{v}=\sigma\}}{\hat{\operatorname{Pr}}\{\tilde{s}=0\}}=\frac{\hat{\operatorname{Pr}}\{\tilde{s}=0 \mid \tilde{v}=\sigma\} \phi}{1-\phi} \\
= & \frac{\phi}{1-\phi}[\hat{\operatorname{Pr}}\{\tilde{s}=0 \mid \tilde{v}=\sigma, \tilde{\varepsilon}=1\} \hat{\operatorname{Pr}}\{\tilde{\varepsilon}=1 \mid \tilde{v}=\sigma\} \\
& +\hat{\operatorname{Pr}}\{\tilde{s}=0 \mid \tilde{v}=\sigma, \tilde{\varepsilon}=0\} \hat{\operatorname{Pr}}\{\tilde{\varepsilon}=0 \mid \tilde{v}=\sigma\}] \\
= & \frac{\phi}{1-\phi}[0 \cdot(a+b)+(1-\phi)(1-a-b)]=(1-a-b) \phi,
\end{aligned}
$$

as in (2). Q.E.D.

Proof of Lemma 2: If $\tilde{s}=0$, it is optimal for the firm to drop the project as $E[\tilde{v} \mid \tilde{s}=0]-1=\sigma \phi_{\mathrm{D}}-1<\sigma \phi-1 \leq 0$; its expected profits are then zero. If $\tilde{s}=\sigma$, then the firm will undertake the project if and only if $E[\tilde{v} \mid \tilde{s}=\sigma]-1=$ $\sigma \phi_{\mathrm{U}}-1>0$, which, using (1), is equivalent to $a>1-\frac{\sigma-1}{\sigma(1-\phi)}$. When that is the case, the firm's value is equal to

$$
\begin{aligned}
F & =1+\operatorname{Pr}\{\tilde{s}=\sigma\}(E[\tilde{v} \mid \tilde{s}=\sigma]-1)+\operatorname{Pr}\{\tilde{s}=0\} \cdot 0 \\
& =1+\phi\left(\sigma \phi_{\mathrm{U}}-1\right) \\
& =\phi \sigma[\phi+a(1-\phi)]+(1-\phi),
\end{aligned}
$$

\footnotetext{
${ }^{26}$ In fact, Brown and Sarma (2007) document that CEO overconfidence and CEO compensation jointly affect the frequency of a firm's corporate acquisitions.
} 
as in (3). Otherwise, the project is never undertaken and the value of the firm is simply its cash value of one. Q.E.D.

Proof of Lemma 3: Suppose that the manager observes $\tilde{s}=\sigma$. If the manager chooses to undertake the project, his expected utility is

$$
\hat{\phi}_{\mathrm{U}}\left[\delta_{\mathrm{M}}+(1-r) \delta_{\mathrm{H}}\right]+\left(1-\hat{\phi}_{\mathrm{U}}\right)(0)=\hat{\phi}_{\mathrm{U}}\left[\delta_{\mathrm{M}}+(1-r) \delta_{\mathrm{H}}\right] .
$$

If, instead, the manager chooses not to undertake the project, his expected utility is $\delta_{\mathrm{M}}$. Thus, the manager will choose to undertake the project if and only if $\hat{\phi}_{\mathrm{U}}\left[\delta_{\mathrm{M}}+(1-r) \delta_{\mathrm{H}}\right]>\delta_{\mathrm{M}}$, which, using (1), is equivalent to (4). Suppose now that the manager observes $\tilde{s}=0$. If the manager chooses to undertake the project, his expected utility is

$$
\hat{\phi}_{\mathrm{D}}\left[\delta_{\mathrm{M}}+(1-r) \delta_{\mathrm{H}}\right]+\left(1-\hat{\phi}_{\mathrm{D}}\right)(0)=\hat{\phi}_{\mathrm{D}}\left[\delta_{\mathrm{M}}+(1-r) \delta_{\mathrm{H}}\right] .
$$

If, instead, the manager chooses not to undertake the project, his expected utility is $\delta_{\mathrm{M}}$. Thus, the manager will choose to undertake the project if and only if $\hat{\phi}_{\mathrm{D}}\left[\delta_{\mathrm{M}}+(1-r) \delta_{\mathrm{H}}\right]>\delta_{\mathrm{M}}$, which, using (2), is equivalent to (5). Q.E.D.

Proof of Proposition 1: As illustrated in Figure 3, when the slope of the firm's iso-profit curves is smaller than that of the manager's iso-utility curves, the firm's expected profits are maximized at the point where the lower boundary of (IC), $\delta_{\mathrm{H}}=\hat{\kappa}_{\mathrm{U}} \delta_{\mathrm{M}}$, intersects the boundary of (PC) (i.e., the line where (PC) is satisfied with an equality sign). The solution is given by (9). Otherwise, the firm's expected profits are maximized at the point where the upper boundary of (IC), $\delta_{\mathrm{H}}=\hat{\kappa}_{\mathrm{D}} \delta_{\mathrm{M}}$, intersects the boundary of (PC). The solution is given by (10). Under (IC), the firm's iso-profit curves are given by

$$
\begin{aligned}
\bar{\pi} & =E[\tilde{\pi}]=\operatorname{Pr}\{\tilde{s}=\sigma\}\left[-1+\operatorname{Pr}\{\tilde{v}=\sigma \mid \tilde{s}=\sigma\}\left(\sigma-\delta_{\mathrm{M}}-\delta_{\mathrm{H}}\right)\right]+\operatorname{Pr}\{\tilde{s}=0\}\left(-\delta_{\mathrm{M}}\right) \\
& =-\phi+\phi \phi_{\mathrm{U}}\left(\sigma-\delta_{\mathrm{M}}-\delta_{\mathrm{H}}\right)-(1-\phi) \delta_{\mathrm{M}},
\end{aligned}
$$

and their slope is equal to

$$
m_{\pi} \equiv-\left(1+\frac{1-\phi}{\phi \phi_{\mathrm{U}}}\right) .
$$

From (PC), the slope of the manager's iso-utility curves is equal to

$$
\hat{m}_{u} \equiv-\frac{1}{1-r}\left(1+\frac{1-\phi}{\phi \hat{\phi}_{\mathrm{U}}}\right) .
$$

The iso-utility curves are steeper than the iso-profit curves if $\hat{m}_{u} \leq m_{\pi}$, which, using (1) and the fact that $\hat{\phi}_{\mathrm{U}}=\phi_{\mathrm{U}}+b(1-\phi)$, is always the case when (7) holds and is equivalent to (8) otherwise. This completes the proof. Q.E.D.

Proof of Corollary 1 : (i) When $r>r^{*}$ or $b<b^{*}$, the optimal contract is given by (9). Clearly $\frac{\partial \delta_{M}}{\partial b}=0$. From (1), we have $\frac{\partial \hat{\phi}_{\mathrm{U}}}{\partial b}=1-\phi>0$, and so

$$
\frac{\partial \delta_{\mathrm{H}}}{\partial b}=\frac{\partial \delta_{\mathrm{H}}}{\partial \hat{\phi}_{\mathrm{U}}} \frac{\partial \hat{\phi}_{\mathrm{U}}}{\partial b}=-\frac{\bar{u}}{\hat{\phi}_{\mathrm{U}}^{2}(1-r)}(1-\phi)<0 .
$$


(ii) When $r<r^{*}$ and $b>b^{*}$, the optimal contract is given by (10). From (2), we have $\frac{\partial \hat{\phi}_{\mathrm{D}}}{\partial b}=-\phi<0$, and so

$$
\frac{\partial \delta_{\mathrm{M}}}{\partial b}=\frac{\partial \delta_{\mathrm{M}}}{\partial \hat{\phi}_{\mathrm{D}}} \frac{\partial \hat{\phi}_{\mathrm{D}}}{\partial b}=\frac{\bar{u}}{\phi}(-\phi)=-\bar{u}<0
$$

and

$$
\frac{\partial \delta_{\mathrm{H}}}{\partial b}=\frac{\partial \delta_{\mathrm{H}}}{\partial \hat{\phi}_{\mathrm{D}}} \frac{\partial \hat{\phi}_{\mathrm{D}}}{\partial b}=-\frac{\bar{u}}{\phi(1-r)}(-\phi)=\frac{\bar{u}}{1-r}>0 .
$$

This completes the proof. Q.E.D.

Proof of Proposition 2: (i) Suppose first that $r>r^{*}$ or $b<b^{*}$. The optimal compensation contract is then given by (9). As shown in Corollary 1, this contract is such that $\frac{\partial \delta_{\mathrm{M}}}{\partial b}=0$ and $\frac{\partial \delta_{\mathrm{H}}}{\partial b}<0$. As $b$ increases, the manager receives strictly less compensation in the high state and the same compensation in the medium state. Because the contract is incentive compatible (i.e., the project is undertaken if and only if $\tilde{s}=\sigma$ ) but cheaper, firm value clearly goes up.

Suppose instead that $r<r^{*}$ and $b>b^{*}$. The optimal compensation contract is then given by (10). Since the contract is incentive compatible, the value of the firm is

$$
\begin{aligned}
F & =1+E[\tilde{\rho}-\tilde{w}] \\
& =\operatorname{Pr}\{\tilde{s}=\sigma\} \operatorname{Pr}\{\tilde{v}=\sigma \mid \tilde{s}=\sigma\}\left(\sigma-\delta_{\mathrm{M}}-\delta_{\mathrm{H}}\right)+\operatorname{Pr}\{\tilde{s}=0\}\left(1-\delta_{\mathrm{M}}\right) \\
& =\phi \phi_{\mathrm{U}}\left(\sigma-\delta_{\mathrm{M}}-\delta_{\mathrm{H}}\right)+(1-\phi)\left(1-\delta_{\mathrm{M}}\right) .
\end{aligned}
$$

Using (A4) and (A5), we have

$$
\begin{aligned}
\frac{\partial F}{\partial b} & =-\phi \phi_{\mathrm{U}}\left(\frac{\partial \delta_{\mathrm{M}}}{\partial b}+\frac{\partial \delta_{\mathrm{H}}}{\partial b}\right)-(1-\phi) \frac{\partial \delta_{\mathrm{M}}}{\partial b}=-\phi \phi_{\mathrm{U}}\left(-\bar{u}+\frac{\bar{u}}{1-r}\right)-(1-\phi)(-\bar{u}) \\
& =\frac{\bar{u}}{1-r}\left[-r \phi \phi_{\mathrm{U}}+(1-\phi)(1-r)\right] .
\end{aligned}
$$

Using the fact that $r<r^{*}$, this last expression can be shown to be positive.

(ii) Let us denote the value of the firm by $F$. To establish this result, we need to show that $\frac{\partial F}{\partial b}$, evaluated at $b=0$ and keeping $\sigma \phi$ fixed, is greater for small values of $\phi$ and $a$ and for large values of $\sigma$ and $r$. When $b$ is arbitrarily close to zero, it is the case that $b<b^{*}$, and so the optimal compensation contract is given by (9). Since this contract is incentive compatible, the value of the firm is

$$
\begin{aligned}
F & =1+E[\tilde{\rho}-\tilde{w}] \\
& =\operatorname{Pr}\{\tilde{s}=\sigma\} \operatorname{Pr}\{\tilde{v}=\sigma \mid \tilde{s}=\sigma\}\left(\sigma-\delta_{\mathrm{M}}-\delta_{\mathrm{H}}\right)+\operatorname{Pr}\{\tilde{s}=0\}\left(1-\delta_{\mathrm{M}}\right) \\
& =\phi \phi_{\mathrm{U}}\left(\sigma-\delta_{\mathrm{M}}-\delta_{\mathrm{H}}\right)+(1-\phi)\left(1-\delta_{\mathrm{M}}\right) .
\end{aligned}
$$


Using $\frac{\partial \delta_{\mathrm{M}}}{\partial b}=0$ and $\frac{\partial \delta_{\mathrm{H}}}{\partial b}=-\frac{\bar{u}}{\hat{\phi}_{\mathrm{U}}^{2}(1-r)}(1-\phi)$ from the proof of Corollary 1 , we have

$$
\frac{\partial F}{\partial b}=-\phi \phi_{\mathrm{U}}\left(\frac{\partial \delta_{\mathrm{M}}}{\partial b}+\frac{\partial \delta_{\mathrm{H}}}{\partial b}\right)-(1-\phi) \frac{\partial \delta_{\mathrm{M}}}{\partial b}=\frac{\phi \phi_{\mathrm{U}}(1-\phi) \bar{u}}{\hat{\phi}_{\mathrm{U}}^{2}(1-r)} .
$$

Since $\frac{\partial F}{\partial b}$ does not depend on $\sigma$, we only need to show that $\frac{\partial^{2} F}{\partial \phi \partial b}<0, \frac{\partial^{2} F}{\partial a \partial b}<0$ and $\frac{\partial^{2} F}{\partial r \partial b}>0$ at $b=0$ to establish the result. Using (1), it is straightforward to show that (A7) is decreasing in $\phi$, decreasing in $a$, and increasing in $r$ at $b=0$. Q.E.D.

Proof of Proposition 3: As in Proposition 1, the solution lies on the lower (upper) boundary of the (IC) set when the manager's iso-utility curves are steeper (flatter) than the firm's iso-profit curves, and the condition for this to be the case, $b \leq b^{*}\left(b>b^{*}\right)$, is derived in exactly the same way as in that proposition. When $b \leq b^{*}$, the solution to (11) lies at the intersection of the lower boundary of the (IC) set and the zero-profit curve, that is, it must satisfy $\delta_{\mathrm{H}}=\hat{\kappa}_{\mathrm{U}} \delta_{\mathrm{M}}$ and (ZP). The solution is given by (12). When $b>b^{*}$, the solution to (11) lies at the intersection of the upper boundary of the (IC) set and the zero-profit curve, that is, it must satisfy $\delta_{\mathrm{H}}=\hat{\kappa}_{\mathrm{D}} \delta_{\mathrm{M}}$ and (ZP). The solution, after observing from (1) and (2) that $\phi_{\mathrm{U}}=1-\frac{1-\phi}{\phi} \phi_{\mathrm{D}}$, is given by (13). Q.E.D.

Proof of Proposition 4: (i) When $b<b^{*}$, the equilibrium contract is given by (12). Since $\hat{\phi}_{\mathrm{U}}=\phi_{\mathrm{U}}+b(1-\phi)$, straightforward but tedious calculations show that

$$
\frac{\partial \delta_{\mathrm{M}}}{\partial b}=\frac{\partial \delta_{\mathrm{M}}}{\partial \hat{\phi}_{\mathrm{U}}} \frac{\partial \hat{\phi}_{\mathrm{U}}}{\partial b}=\frac{\phi \phi_{\mathrm{U}}\left(1-\phi+\sigma \phi \phi_{\mathrm{U}}\right)(1-r)}{\left[\hat{\phi}_{\mathrm{U}}(1-\phi)(1-r)+\phi \phi_{\mathrm{U}}\left(1-r \hat{\phi}_{\mathrm{U}}\right)\right]^{2}}(1-\phi)>0
$$

and

$$
\frac{\partial \delta_{\mathrm{H}}}{\partial b}=\frac{\partial \delta_{\mathrm{H}}}{\partial \hat{\phi}_{\mathrm{U}}} \frac{\partial \hat{\phi}_{\mathrm{U}}}{\partial b}=-\frac{\left(1-\phi+\phi \phi_{\mathrm{U}}\right)\left(1-\phi+\sigma \phi \phi_{\mathrm{U}}\right)(1-r)}{\left[\hat{\phi}_{\mathrm{U}}(1-\phi)(1-r)+\phi \phi_{\mathrm{U}}\left(1-r \hat{\phi}_{\mathrm{U}}\right)\right]^{2}}(1-\phi)<0 .
$$

With this contract, the manager's expected utility is

$$
\begin{aligned}
E[\tilde{u}] & =\operatorname{Pr}\{\tilde{s}=\sigma\} \operatorname{Pr}\{\tilde{v}=\sigma \mid \tilde{s}=\sigma\}\left[\delta_{\mathrm{M}}+(1-r) \delta_{\mathrm{H}}\right]+\operatorname{Pr}\{\tilde{s}=0\} \delta_{\mathrm{M}} \\
& =\phi \phi_{\mathrm{U}}\left[\delta_{\mathrm{M}}+(1-r) \delta_{\mathrm{H}}\right]+(1-\phi) \delta_{\mathrm{M}} \\
& =\frac{\left(1-\phi+\sigma \phi \phi_{\mathrm{U}}\right)\left[\phi \phi_{\mathrm{U}}+(1-\phi) \hat{\phi}_{\mathrm{U}}\right](1-r)}{\hat{\phi}_{\mathrm{U}}(1-\phi)(1-r)+\phi \phi_{\mathrm{U}}\left(1-r \hat{\phi}_{\mathrm{U}}\right)}
\end{aligned}
$$

and

$$
\frac{\partial E[\tilde{u}]}{\partial b}=\frac{\partial E[\tilde{u}]}{\partial \hat{\phi}_{\mathrm{U}}} \frac{\partial \hat{\phi}_{\mathrm{U}}}{\partial b}=\frac{\phi \phi_{\mathrm{U}}\left(1-\phi+\phi \phi_{\mathrm{U}}\right)\left(1-\phi+\sigma \phi \phi_{\mathrm{U}}\right) r(1-r)}{\left[\hat{\phi}_{\mathrm{U}}(1-\phi)(1-r)+\phi \phi_{\mathrm{U}}\left(1-r \hat{\phi}_{\mathrm{U}}\right)\right]^{2}}(1-\phi)>0 .
$$


(ii) When $b \geq b^{*}$, the equilibrium contract is given by (13). Since $\hat{\phi}_{\mathrm{D}}=\phi_{\mathrm{D}}-b \phi$ and $\sigma \phi_{\mathrm{D}}<\sigma \phi<1$, it is straightforward to show that

$$
\frac{\partial \delta_{\mathrm{M}}}{\partial b}=\frac{\partial \delta_{\mathrm{M}}}{\partial \hat{\phi}_{\mathrm{D}}} \frac{\partial \hat{\phi}_{\mathrm{D}}}{\partial b}=\frac{\left(\phi-\phi_{\mathrm{D}}+\phi \phi_{\mathrm{D}}\right)\left[\sigma \phi+(1-\phi)\left(1-\sigma \phi_{\mathrm{D}}\right)\right](1-r)}{\left[(1-r) \hat{\phi}_{\mathrm{D}}+\phi\left(1-\hat{\phi}_{\mathrm{D}}\right)-(1-\phi) \phi_{\mathrm{D}}\left(1-r \hat{\phi}_{\mathrm{D}}\right)\right]^{2}}(-\phi)<0
$$

and

$$
\frac{\partial \delta_{\mathrm{H}}}{\partial b}=\frac{\partial \delta_{\mathrm{H}}}{\partial \hat{\phi}_{\mathrm{D}}} \frac{\partial \hat{\phi}_{\mathrm{D}}}{\partial b}=-\frac{\left(1-\phi_{\mathrm{D}}+\phi \phi_{\mathrm{D}}\right)\left[\sigma \phi+(1-\phi)\left(1-\sigma \phi_{\mathrm{D}}\right)\right](1-r)}{\left[(1-r) \hat{\phi}_{\mathrm{D}}+\phi\left(1-\hat{\phi}_{\mathrm{D}}\right)-(1-\phi) \phi_{\mathrm{D}}\left(1-r \hat{\phi}_{\mathrm{D}}\right)\right]^{2}}(-\phi)>0 .
$$

With this contract, the manager's expected utility is

$$
\begin{aligned}
E[\tilde{u}] & =\operatorname{Pr}\{\tilde{s}=\sigma\} \operatorname{Pr}\{\tilde{v}=\sigma \mid \tilde{s}=\sigma\}\left[\delta_{\mathrm{M}}+(1-r) \delta_{\mathrm{H}}\right]+\operatorname{Pr}\{\tilde{s}=0\} \delta_{\mathrm{M}} \\
& =\phi \phi_{\mathrm{U}}\left[\delta_{\mathrm{M}}+(1-r) \delta_{\mathrm{H}}\right]+(1-\phi) \delta_{\mathrm{M}} \\
& =\frac{\left[\sigma \phi+(1-\phi)\left(1-\sigma \phi_{\mathrm{D}}\right)\right]\left[\phi-(1-\phi)\left(\phi_{\mathrm{D}}-\hat{\phi}_{\mathrm{D}}\right)\right](1-r)}{(1-r) \hat{\phi}_{\mathrm{D}}+\phi\left(1-\hat{\phi}_{\mathrm{D}}\right)-(1-\phi) \phi_{\mathrm{D}}\left(1-r \hat{\phi}_{\mathrm{D}}\right)},
\end{aligned}
$$

and

$$
\begin{aligned}
& \frac{\partial E[\tilde{u}]}{\partial b}=\frac{\partial E[\tilde{u}]}{\partial \hat{\phi}_{\mathrm{D}}} \frac{\partial \hat{\phi}_{\mathrm{D}}}{\partial b} \\
& =\frac{\left[\sigma \phi+(1-\phi)\left(1-\sigma \phi_{\mathrm{D}}\right)\right]\left[\phi-\phi_{\mathrm{D}}\left(1-\phi^{2}\right)+\phi_{\mathrm{D}}^{2}(1-\phi)^{2}\right] r(1-r)}{\left[(1-r) \hat{\phi}_{\mathrm{D}}+\phi\left(1-\hat{\phi}_{\mathrm{D}}\right)-(1-\phi) \phi_{\mathrm{D}}\left(1-r \hat{\phi}_{\mathrm{D}}\right)\right]^{2}}(-\phi)<0 .
\end{aligned}
$$

This completes the proof. Q.E.D.

Proof of Proposition 5: When the two firms competing for the manager's services are different, it is no longer necessary that both firms break even in equilibrium. Instead, only one firm is forced to break even and the other can attract the manager by offering a compensation contract that is infinitesimally better than the cheapest contract of its competitor. The following lemma establishes this result formally.

LEMMA A1: Let us index the firm that attracts the manager by $i \in\{\mathrm{G}, \mathrm{V}\}$ and the one that must operate without a manager by $j$. In equilibrium, the manager's compensation contract $\left\{\delta_{\mathrm{L}}, \delta_{\mathrm{M}}, \delta_{\mathrm{H}}\right\}$ must satisfy $(I C), E\left[\tilde{\pi}_{i}\right] \geq 0$, and $E\left[\tilde{\pi}_{j}\right]=0$, and it must be the case that all the other (IC) contracts $\left\{\delta_{\mathrm{L}}^{\prime}, \delta_{\mathrm{M}}^{\prime}, \delta_{\mathrm{H}}^{\prime}\right\}$ satisfy $E\left[\tilde{\pi}_{j}^{\prime}\right] \leq 0$ or $\hat{\mathrm{E}}\left[\tilde{u}^{\prime}\right]<\hat{\mathrm{E}}[\tilde{u}]$.

Proof: Suppose that $\left\{\delta_{\mathrm{L}}, \delta_{\mathrm{M}}, \delta_{\mathrm{H}}\right\}$ is an equilibrium contract. If there is another (IC) contract $\left\{\delta_{\mathrm{L}}^{\prime}, \delta_{\mathrm{M}}^{\prime}, \delta_{\mathrm{H}}^{\prime}\right\}$ that satisfies $E\left[\tilde{\pi}_{j}^{\prime}\right]>0$ and $\hat{\mathrm{E}}\left[\tilde{u}^{\prime}\right] \geq \hat{\mathrm{E}}[\tilde{u}]$, then firm $j$ could attract the manager and make itself profitable by offering this contract, a clear contradiction. Similarly, we cannot have $E\left[\tilde{\pi}_{i}\right]>0$ and $E\left[\tilde{\pi}_{j}\right]>0$ either, as one firm could attract the manager by offering him a marginally better contract that keeps its expected profits positive. If $E\left[\tilde{\pi}_{j}\right]<0$, then firm $i$ can still attract the manager while making itself more profitable by choosing a 
contract with $\delta_{\mathrm{L}}^{\prime}=\delta_{\mathrm{L}}-\varepsilon$ and $\left\{\delta_{\mathrm{M}}^{\prime}, \delta_{\mathrm{H}}^{\prime}\right\}=\left\{\delta_{\mathrm{M}}, \delta_{\mathrm{L}}\right\}$ if $\delta_{\mathrm{L}}>0$, or a contract with $\delta_{\mathrm{L}}^{\prime}=0, \delta_{\mathrm{M}}^{\prime}=\delta_{\mathrm{M}}-\varepsilon$ and $\delta_{\mathrm{H}}^{\prime}=\delta_{\mathrm{H}}-\varepsilon \frac{\delta_{\mathrm{H}}}{\delta_{\mathrm{M}}}$ if $\delta_{\mathrm{L}}=0$. Indeed, it is easy to verify that these contracts still satisfy (IC) and, when $\varepsilon$ is close enough to zero, it is still the case that $E\left[\tilde{\pi}_{j}^{\prime}\right]<0$. Because $\left\{\delta_{\mathrm{L}}^{\prime}, \delta_{\mathrm{M}}^{\prime}, \delta_{\mathrm{H}}^{\prime}\right\}$ is cheaper than $\left\{\delta_{\mathrm{L}}, \delta_{\mathrm{M}}, \delta_{\mathrm{H}}\right\}$, firm $i$ is more profitable, again a contradiction to $\left\{\delta_{\mathrm{L}}, \delta_{\mathrm{M}}, \delta_{\mathrm{H}}\right\}$ being an equilibrium contract.

Lemma A1 implies that the firm that attracts the manager will seek to find the cheapest (IC) contract with which the other firm's maximum expected profits are zero. The following lemma simplifies the search for this contract.

Lemma A2: Suppose that a firm starts with $A \geq 1$ in cash. Then the cheapest (IC) contract that satisfies $\hat{\mathrm{E}}[\tilde{u}]=\bar{u}$ depends on the size of $b$ relative to $b^{*}$ defined in (8) and to

$$
\bar{b} \equiv \frac{r \phi_{\mathrm{U}}\left(1-\phi_{\mathrm{U}}\right)}{(1-\phi)\left(1-r+r \phi_{\mathrm{U}}\right)}<b^{*}
$$

- If $b \leq \bar{b}$, then the cheapest compensation contract is

$$
\delta_{\mathrm{L}}=\min \{\bar{u}, A-1\}, \quad \delta_{\mathrm{M}}=\bar{u}-\delta_{\mathrm{L}}, \quad \delta_{\mathrm{H}}=\frac{\left(1-\hat{\phi}_{\mathrm{U}}\right)\left(\bar{u}-\delta_{\mathrm{L}}\right)}{\hat{\phi}_{\mathrm{U}}(1-r)} .
$$

- If $\bar{b}<b \leq b^{*}$, then the cheapest compensation contract is

$$
\delta_{\mathrm{L}}=0, \quad \delta_{\mathrm{M}}=\bar{u}, \quad \delta_{\mathrm{H}}=\frac{\left(1-\hat{\phi}_{\mathrm{U}}\right) \bar{u}}{\hat{\phi}_{\mathrm{U}}(1-r)} .
$$

- If $b>b^{*}$, then the cheapest compensation contract is

$$
\delta_{\mathrm{L}}=0, \quad \delta_{\mathrm{M}}=\frac{\hat{\phi}_{\mathrm{D}} \bar{u}}{\phi}, \quad \delta_{\mathrm{H}}=\frac{\left(1-\hat{\phi}_{\mathrm{D}}\right) \bar{u}}{\phi(1-r)} .
$$

Proof: We know from the proof of Proposition 1 that, when the firm must set $\delta_{\mathrm{L}}=0$ (i.e., when $A=1$ ), the cheapest contract must satisfy $\frac{\delta_{\mathrm{H}}}{\delta_{\mathrm{M}}}=\hat{\kappa}_{\mathrm{U}}$ and is given by (9) if $b \leq b^{*}$, and the cheapest contract must satisfy $\frac{\delta_{H}}{\delta_{M}}=\hat{\kappa}_{D}$ and is given by (10) if $b>b^{*}$. In both cases, we need to check if setting $\delta_{\mathrm{L}}$ above zero and lowering $\delta_{\mathrm{M}}$ and $\delta_{\mathrm{H}}$ is optimal.

First, suppose that $b \leq b^{*}$ and that the firm sets $\delta_{\mathrm{L}}=\varepsilon>0$. Because $b \leq$ $b^{*}$, it is optimal for the firm to set $\delta_{\mathrm{H}}^{\prime}=\hat{\kappa}_{\mathrm{U}} \delta_{\mathrm{M}}^{\prime}=\frac{1-\hat{\phi}_{\mathrm{U}}}{\hat{\phi}_{\mathrm{U}}} \frac{\delta_{\mathrm{M}}^{\prime}}{1-r}$. For the manager to be indifferent about this new contract, we must have

$$
\begin{aligned}
0 & =\hat{\mathrm{E}}\left[\tilde{u}^{\prime}\right]-\hat{\mathrm{E}}[\tilde{u}] \\
& =\left(\delta_{\mathrm{L}}^{\prime}-\delta_{\mathrm{L}}\right)+\phi \hat{\phi}_{\mathrm{U}}\left[\left(\delta_{\mathrm{M}}^{\prime}-\delta_{\mathrm{M}}\right)+(1-r)\left(\delta_{\mathrm{H}}^{\prime}-\delta_{\mathrm{H}}\right)\right]+(1-\phi)\left(\delta_{\mathrm{M}}^{\prime}-\delta_{\mathrm{M}}\right) \\
& =\left(\delta_{\mathrm{L}}^{\prime}-\delta_{\mathrm{L}}\right)+\phi \hat{\phi}_{\mathrm{U}}\left[\left(\delta_{\mathrm{M}}^{\prime}-\delta_{\mathrm{M}}\right)+\frac{1-\hat{\phi}_{\mathrm{U}}}{\hat{\phi}_{\mathrm{U}}}\left(\delta_{\mathrm{M}}^{\prime}-\delta_{\mathrm{M}}\right)\right]+(1-\phi)\left(\delta_{\mathrm{M}}^{\prime}-\delta_{\mathrm{M}}\right) \\
& =\varepsilon+\left(\delta_{\mathrm{M}}^{\prime}-\delta_{\mathrm{M}}\right)
\end{aligned}
$$


and so $\delta_{\mathrm{M}}^{\prime}=\delta_{\mathrm{M}}-\varepsilon$ and $\delta_{\mathrm{H}}^{\prime}=\delta_{\mathrm{H}}-\frac{1-\hat{\phi}_{\mathrm{U}}}{\hat{\phi}_{\mathrm{U}}} \frac{\varepsilon}{1-r}$. The effect that this has on the firm's expected compensation expense is

$$
\begin{aligned}
E\left[\tilde{w}^{\prime}\right]-E[\tilde{w}] & =\left(\delta_{\mathrm{L}}^{\prime}-\delta_{\mathrm{L}}\right)+\phi \phi_{\mathrm{U}}\left[\left(\delta_{\mathrm{M}}^{\prime}-\delta_{\mathrm{M}}\right)+\left(\delta_{\mathrm{H}}^{\prime}-\delta_{\mathrm{H}}\right)\right]+(1-\phi)\left(\delta_{\mathrm{M}}^{\prime}-\delta_{\mathrm{M}}\right) \\
& =\varepsilon-\phi \phi_{\mathrm{U}}\left[\varepsilon+\frac{1-\hat{\phi}_{\mathrm{U}}}{\hat{\phi}_{\mathrm{U}}} \frac{\varepsilon}{1-r}\right]+(1-\phi) \varepsilon \\
& =\frac{\varepsilon \phi}{(1-r) \hat{\phi}_{\mathrm{U}}}\left[\left(\hat{\phi}_{\mathrm{U}}-\phi_{\mathrm{U}}\right)-r \hat{\phi}_{\mathrm{U}}\left(1-\phi_{\mathrm{U}}\right)\right] \\
& =\frac{\varepsilon \phi}{(1-r) \hat{\phi}_{\mathrm{U}}}\left\{b(1-\phi)\left[1-r\left(1-\phi_{\mathrm{U}}\right)\right]-r \phi_{\mathrm{U}}\left(1-\phi_{\mathrm{U}}\right)\right\},
\end{aligned}
$$

where the last equality is obtained by using the fact that $\hat{\phi}_{\mathrm{U}}=\phi_{\mathrm{U}}+b(1-\phi)$ and by simplifying. The new contract $\left\{\delta_{\mathrm{L}}^{\prime}, \delta_{\mathrm{M}}^{\prime}, \delta_{\mathrm{H}}^{\prime}\right\}$ is cheaper than $\left\{\delta_{\mathrm{L}}, \delta_{\mathrm{M}}\right.$, $\left.\delta_{\mathrm{H}}\right\}$ if and only if (A12) is negative, that is, if and only if $b \leq \bar{b}$, where $\bar{b}$ is as defined in (A8). A straightforward comparison of (A8) and (8) shows that $\bar{b}<b^{*}$. Thus, it is optimal for the firm to set $\delta_{\mathrm{L}}$ as large as possible when $b \leq \bar{b}$, and to set $\delta_{\mathrm{L}}=0$ when $b \in\left(\bar{b}, b^{*}\right]$. This yields (A9) and (A10).

Now, suppose that $b>b^{*}$ and that the firm sets $\delta_{\mathrm{L}}=\varepsilon>0$. Because $b>b^{*}$, it is optimal for the firm to set $\delta_{\mathrm{H}}^{\prime}=\hat{\kappa}_{\mathrm{D}} \delta_{\mathrm{M}}^{\prime}=\frac{1-\hat{\phi}_{\mathrm{D}}}{\hat{\phi}_{\mathrm{D}}} \frac{\delta_{\mathrm{M}}^{\prime}}{1-r}$. For the manager to be indifferent about this new contract, we must have

$$
\begin{aligned}
0= & \hat{\mathrm{E}}\left[\tilde{u}^{\prime}\right]-\hat{\mathrm{E}}[\tilde{u}]=\left(\delta_{\mathrm{L}}^{\prime}-\delta_{\mathrm{L}}\right)+\phi \hat{\phi}_{\mathrm{U}}\left[\left(\delta_{\mathrm{M}}^{\prime}-\delta_{\mathrm{M}}\right)+(1-r)\left(\delta_{\mathrm{H}}^{\prime}-\delta_{\mathrm{H}}\right)\right] \\
& +(1-\phi)\left(\delta_{\mathrm{M}}^{\prime}-\delta_{\mathrm{M}}\right)=\left(\delta_{\mathrm{L}}^{\prime}-\delta_{\mathrm{L}}\right)+\phi \hat{\phi}_{\mathrm{U}}\left[\left(\delta_{\mathrm{M}}^{\prime}-\delta_{\mathrm{M}}\right)+\frac{1-\hat{\phi}_{\mathrm{D}}}{\hat{\phi}_{\mathrm{D}}}\left(\delta_{\mathrm{M}}^{\prime}-\delta_{\mathrm{M}}\right)\right] \\
= & \varepsilon+\left(\delta_{\mathrm{M}}^{\prime}-\delta_{\mathrm{M}}\right)\left[\frac{\phi \hat{\phi}_{\mathrm{U}}}{\hat{\phi}_{\mathrm{D}}}+(1-\phi)\right]=\varepsilon+\left(\delta_{\mathrm{M}}^{\prime}-\delta_{\mathrm{M}}\right) \frac{1-\phi}{1-\hat{\phi}_{\mathrm{U}}},
\end{aligned}
$$

where the last equality is obtained using the fact that $\frac{1-\hat{\phi}_{\mathrm{U}}}{\hat{\phi}_{\mathrm{D}}}=\frac{1-\phi}{\phi}$ and simplifying. This implies that

$$
\delta_{\mathrm{M}}^{\prime}=\delta_{\mathrm{M}}-\varepsilon \frac{1-\hat{\phi}_{\mathrm{U}}}{1-\phi} \quad \text { and } \quad \delta_{\mathrm{H}}^{\prime}=\delta_{\mathrm{H}}-\frac{1-\hat{\phi}_{\mathrm{D}}}{\hat{\phi}_{\mathrm{D}}} \frac{\varepsilon\left(1-\hat{\phi}_{\mathrm{U}}\right)}{(1-r)(1-\phi)}=\delta_{\mathrm{H}}-\varepsilon \frac{1-\hat{\phi}_{\mathrm{D}}}{(1-r) \phi}
$$


The effect that this has on the firm's expected compensation expense is

$$
\begin{aligned}
E\left[\tilde{w}^{\prime}\right]- & E[\tilde{w}]=\left(\delta_{\mathrm{L}}^{\prime}-\delta_{\mathrm{L}}\right)+\phi \phi_{\mathrm{U}}\left[\left(\delta_{\mathrm{M}}^{\prime}-\delta_{\mathrm{M}}\right)+\left(\delta_{\mathrm{H}}^{\prime}-\delta_{\mathrm{H}}\right)\right]+(1-\phi)\left(\delta_{\mathrm{M}}^{\prime}-\delta_{\mathrm{M}}\right) \\
= & \varepsilon-\phi \phi_{\mathrm{U}}\left[\varepsilon \frac{1-\hat{\phi}_{\mathrm{U}}}{1-\phi}+\varepsilon \frac{1-\hat{\phi}_{\mathrm{D}}}{(1-r) \phi}\right]-(1-\phi) \varepsilon \frac{1-\hat{\phi}_{\mathrm{U}}}{1-\phi} \\
& =\frac{\varepsilon\left[(1-r) \phi(1-\phi)-(1-r) \phi^{2} \phi_{\mathrm{U}}\left(1-\hat{\phi}_{\mathrm{U}}\right)-\phi(1-\phi) \phi_{\mathrm{U}}\left(1-\hat{\phi}_{\mathrm{D}}\right)-(1-r) \phi(1-\phi)\left(1-\hat{\phi}_{\mathrm{U}}\right)\right]}{(1-r) \phi(1-\phi)} \\
& =\frac{\varepsilon\left\{\left(\hat{\phi}_{\mathrm{U}}-\phi_{\mathrm{U}}\right)-r\left[\hat{\phi}_{\mathrm{U}}-\phi_{\mathrm{U}} \hat{\phi}_{\mathrm{D}}\right]\right\}}{1-r}=\frac{\varepsilon\left\{b(1-\phi)-r\left[\phi_{\mathrm{U}}+b(1-\phi)-\phi_{\mathrm{U}} \phi_{\mathrm{D}}+b \phi \phi_{\mathrm{U}}\right]\right\}}{1-r} \\
& =\frac{\varepsilon}{1-r}\left\{b\left[(1-r)(1-\phi)-r \phi \phi_{\mathrm{U}}\right]-r \phi_{\mathrm{U}}\left(1-\phi_{\mathrm{D}}\right)\right\} .
\end{aligned}
$$

The new contract $\left\{\delta_{\mathrm{L}}^{\prime}, \delta_{\mathrm{M}}^{\prime}, \delta_{\mathrm{H}}^{\prime}\right\}$ is cheaper than $\left\{\delta_{\mathrm{L}}, \delta_{\mathrm{M}}, \delta_{\mathrm{H}}\right\}$ if and only if (A13) is negative, that is, if and only if $b \leq \overline{\bar{b}}$, where

$$
\overline{\bar{b}} \equiv \frac{r \phi_{\mathrm{U}}\left(1-\phi_{\mathrm{D}}\right)}{(1-r)(1-\phi)-r \phi \phi_{\mathrm{U}}} .
$$

It is straightforward to verify that $\overline{\bar{b}}<b^{*}$ for all $r<r^{*}$. This implies that there is no $b>b^{*}$ such that $b \leq \overline{\bar{b}}$, and so it is always cheaper for the firm to set $\delta_{\mathrm{L}}=0$ when $b>b^{*}$. This establishes (A11) and completes the proof.

Together, Lemmas A1 and A2 imply that the equilibrium in the labor market with a growth firm and a value firm depends on whether $b \leq \bar{b}, \bar{b}<b \leq b^{*}$, or $b>b^{*}$. Let us first consider the case with $b \leq \bar{b}$. Since $A_{\mathrm{V}}-1 \geq \phi\left(\sigma_{\mathrm{V}} \phi_{\mathrm{U}}-1\right)$, the value firm breaks even when it hires the manager with a contract that has $\delta_{\mathrm{L}}=$ $\phi\left(\sigma_{\mathrm{V}} \phi_{\mathrm{U}}-1\right)$ and $\delta_{\mathrm{M}}=\delta_{\mathrm{H}}=0$. We also know from Lemma 5 that no other (IC) contract will make the value firm profitable. This contract fails to attract the manager if the expected utility that he gets from it, $\hat{\mathrm{E}}[\tilde{u}]=\delta_{\mathrm{L}}=\phi\left(\sigma_{V} \phi_{\mathrm{U}}-1\right)$, can be bettered by the growth firm profitably. For the growth firm, the optimal (i.e., cheapest) contract that provides the manager with this much expected utility is the contract specified in (A10) with $\bar{u}$ replaced by $\phi\left(\sigma_{\mathrm{V}} \phi_{\mathrm{U}}-1\right)$ :

$$
\delta_{\mathrm{L}}=0, \quad \delta_{\mathrm{M}}=\phi\left(\sigma_{V} \phi_{\mathrm{U}}-1\right), \quad \delta_{\mathrm{H}}=\hat{\kappa}_{\mathrm{U}} \delta_{\mathrm{M}}=\frac{\left(1-\hat{\phi}_{\mathrm{U}}\right) \phi\left(\sigma_{V} \phi_{\mathrm{U}}-1\right)}{\hat{\phi}_{\mathrm{U}}(1-r)} .
$$

With this contract, the expected net profits of the growth firm are given by

$$
\begin{aligned}
E\left[\tilde{\pi}_{G}\right] & =-1+\phi \phi_{\mathrm{U}}\left(\sigma_{G}-\delta_{\mathrm{M}}-\delta_{\mathrm{H}}\right)+(1-\phi)\left(1-\delta_{\mathrm{M}}\right) \\
& =-\phi+\phi \phi_{\mathrm{U}}\left[\sigma_{G}-\left(1+\hat{\kappa}_{\mathrm{U}}\right) \delta_{\mathrm{M}}\right]-(1-\phi) \delta_{\mathrm{M}} \\
& =\phi\left(\sigma_{G} \phi_{\mathrm{U}}-1\right)-\left[\phi \phi_{\mathrm{U}}\left(1+\hat{\kappa}_{\mathrm{U}}\right)+(1-\phi)\right] \phi\left(\sigma_{V} \phi_{\mathrm{U}}-1\right) \\
& =\phi\left\{\left(\sigma_{G}-\sigma_{V}\right) \phi_{\mathrm{U}}-\left[\phi_{\mathrm{U}}\left(1+\hat{\kappa}_{\mathrm{U}}\right)-1\right] \phi\left(\sigma_{V} \phi_{\mathrm{U}}-1\right)\right\} .
\end{aligned}
$$


The growth firm attracts the manager if this quantity is greater than zero or, equivalently, after replacing $\hat{\kappa}_{\mathrm{U}}$ by $\frac{\left(1-\hat{\phi}_{\mathrm{U}}\right)}{\hat{\phi}_{\mathrm{U}}(1-r)}$ and rearranging, if

$$
\hat{\phi}_{\mathrm{U}}>\frac{\phi \phi_{\mathrm{U}}\left(\sigma_{V} \phi_{\mathrm{U}}-1\right)}{(1-r) \phi_{\mathrm{U}}\left(\sigma_{G}-\sigma_{V}\right)+\phi\left[1-r\left(1-\phi_{\mathrm{U}}\right)\left(\sigma_{V} \phi_{\mathrm{U}}-1\right)\right]} .
$$

Since $\hat{\phi}_{\mathrm{U}}=\phi_{\mathrm{U}}+b(1-\phi)$, this inequality can easily be shown to be equivalent to

$$
b \leq \frac{\phi_{\mathrm{U}}}{1-\phi} \frac{r \phi\left(1-\phi_{\mathrm{U}}\right)\left(\sigma_{V} \phi_{\mathrm{U}}-1\right)-(1-r) \phi_{\mathrm{U}}\left(\sigma_{G}-\sigma_{V}\right)}{\left[1-r\left(1-\phi_{\mathrm{U}}\right)\right] \phi\left(\sigma_{V} \phi_{\mathrm{U}}-1\right)+(1-r) \phi_{\mathrm{U}}\left(\sigma_{G}-\sigma_{V}\right)} \equiv b^{* *} .
$$

Finally, it is straightforward to show that $b^{* *}<\bar{b}$, and thus the growth firm attracts the manager as long as $b \in\left(b^{* *}, \bar{b}\right]$. When $b \leq b^{* *}$, the growth firm cannot attract the manager away from the value firm. As shown in Proposition 3, the most efficient contract that makes the growth firm break even is given by $\delta_{\mathrm{L}}=0$ and (12) with $\sigma=\sigma_{\mathrm{G}}$. It is easy to verify that the expected utility of the manager with this contract is

$$
\hat{\mathrm{E}}[\tilde{u}]=\phi \hat{\phi}_{\mathrm{U}}\left[\delta_{\mathrm{M}}+(1-r) \delta_{\mathrm{H}}\right]+(1-\phi) \delta_{\mathrm{M}}=\delta_{\mathrm{M}}=\frac{\phi\left(\sigma_{G} \phi_{\mathrm{U}}-1\right)}{1-\phi+\phi \phi_{\mathrm{U}}\left(1+\hat{\kappa}_{\mathrm{U}}\right)} \equiv \bar{u}_{0} .
$$

Thus, from Lemma A2, we know that the cheapest contract for the value firm to provide the agent with this much expected utility is given by $\delta_{\mathrm{L}}=\bar{u}_{0}$ and $\delta_{\mathrm{M}}=\delta_{\mathrm{H}}=0$. With this contract, the expected net profits of the value firm are given by

$$
\begin{aligned}
E\left[\tilde{\pi}_{V}\right] & =-\delta_{\mathrm{L}}-1+\phi \phi_{\mathrm{U}}\left(\sigma_{V}-\delta_{\mathrm{M}}-\delta_{\mathrm{H}}\right)+(1-\phi)\left(1-\delta_{\mathrm{M}}\right)=-\bar{u}_{0}+\phi\left(\sigma_{V} \phi_{\mathrm{U}}-1\right) \\
& =-\frac{\phi\left(\sigma_{G} \phi_{\mathrm{U}}-1\right)}{1-\phi+\phi \phi_{\mathrm{U}}\left(1+\hat{\kappa}_{\mathrm{U}}\right)}+\phi\left(\sigma_{V} \phi_{\mathrm{U}}-1\right),
\end{aligned}
$$

which, when $b \leq b^{* *}$, can be shown to be positive. Therefore, when $b \leq b^{* *}$, the growth firm attracts the manager with this contract.

Let us now turn to the case with $\bar{b}<b \leq b^{*}$. In this case, we know from Lemma A2 that both firms will set $\delta_{\mathrm{L}}=0$ and choose contracts that satisfy $\delta_{\mathrm{H}}=\hat{\kappa}_{\mathrm{U}} \delta_{\mathrm{M}}$. This means that the contracts that make the firms break even are given by (12), with $\sigma=\sigma_{\mathrm{G}}$ for the growth firm and $\sigma=\sigma_{\mathrm{V}}$ for the value firm. Since $\sigma_{\mathrm{G}}>\sigma_{\mathrm{V}}$, the growth firm is profitable and attracts the agent by offering the contract specified by (12), with $\sigma=\sigma_{\mathrm{V}}$.

Finally, let us turn to the case with $b>b^{*}$. In this case, we know from Lemma A2 that both firms will set $\delta_{\mathrm{L}}=0$ and choose contracts that satisfy $\delta_{\mathrm{H}}=\hat{\kappa}_{\mathrm{D}} \delta_{\mathrm{M}}$. This means that the contracts that make the firms break even are given by (13), with $\sigma=\sigma_{\mathrm{G}}$ for the growth firm and $\sigma=\sigma_{\mathrm{V}}$ for the value firm. Again, since $\sigma_{\mathrm{G}}>\sigma_{\mathrm{V}}$, the growth firm is profitable and attracts the agent by offering the contract specified by (13), with $\sigma=\sigma_{\mathrm{V}}$. Q.E.D.

Proof of Corollary 2: (i) Because $\hat{\kappa}_{\mathrm{U}}$ in (4) is decreasing in $b$, it is clearly the case that $\delta_{\mathrm{L}}$ in (14) is increasing in $b$. Thus, since $\delta_{\mathrm{M}}=\delta_{\mathrm{H}}=0$ in (14), an 
increase in $b$ makes the compensation contract more expensive for the firm and makes the manager better off. For (ii) and (iii) results follow directly from the fact that the equilibrium contracts in parts (ii) and (iii) of Proposition 5 have the same form and properties as those of Proposition 3. That is, the results can be established in exactly the same way as the results of Proposition 4. Q.E.D.

\section{Appendix B}

In this appendix, we present a simplified version of the investment problem faced by the firm and show how competition across several firms makes information gathering suboptimal for positive-NPV projects. Similar competitive forces in the paper's main model would imply that projects for which $\sigma \phi$ exceeds the investment cost of one by a sufficient amount would not get investigated further by firms. In the limit as competition increases, only projects for which $\sigma \phi$ is lower than one offer opportunities for information gathering.

Suppose that there are $N \geq 2$ firms in the economy, each with one dollar in cash. A project becomes available, but the project can only be undertaken by one firm. This project costs one dollar and pays off $\tilde{v}$, which is $\sigma>1$ with probability $\phi \in(0,1)$ and zero with probability $1-\phi$. Every firm can choose to undertake the project without gathering any additional information or to gather costless information before making a decision about the project. For simplicity, the information that can be gathered is perfect in that any firm with the information knows whether the project will pay one or zero at the end of the period. However, information gathering takes time and creates opportunities for competitors to steal the project away. In particular, we assume that firms choosing not to gather information can undertake the project before the other firms. Finally, when $M \leq N$ firms decide to undertake the project at the same time, each of these firms gets the project with probability $\frac{1}{M}$.

Proposition B1: (i) When $\sigma \phi \leq 1$, the unique equilibrium is for all $N$ firms to gather information. (ii) When $\sigma \phi>\frac{N-\phi}{N-1}$, the unique equilibrium is for all $N$ firms to undertake the project without gathering any additional information. (iii) When $\sigma \phi \in\left(1, \frac{N-\phi}{N-1}\right]$, the previous two symmetric equilibria are possible, but the information-gathering equilibrium generates greater surplus.

Proof: Without information, the NPV of the project is $\mathrm{E}[\tilde{v}]-1=\sigma \phi-1$. With information, the project's NPV is $\sigma-1>0$ after a firm learns that $\tilde{v}=\sigma$, and it is -1 after a firm learns that $\tilde{v}=0$. Therefore, a firm that gathers information will choose to undertake the project if and only if $\tilde{v}=\sigma$. Also, there is obviously no equilibrium in which any firm undertakes the project when $\sigma \phi \leq 1$, as the NPV of such projects is negative and the worse potential outcome for any firm gathering information is zero. This establishes part (i) of the proposition.

Suppose now that $\sigma \phi>1$. Suppose also that all $N$ firms choose to undertake the project. Each firm then has a probability of $\frac{1}{N}$ of generating the project's NPV of $\sigma \phi-1$ for an expected net profit of $\frac{\sigma \phi-1}{N}>0$. Deviating is never optimal for any one firm as it would mean forgoing this positive value for a sure profit of zero, as the project would go to any of the other $N-1$ firms. 
Suppose, instead, that all $N$ firms choose to gather information about the project before deciding whether to undertake it. With probability $\phi$, these firms discover that $\tilde{v}=\sigma$ and hence choose to undertake the project. With probability $1-\phi$, they find out that $\tilde{v}=0$ and decide against pursuing the project. Because the probability of any one firm actually generating the project's NPV is $\frac{1}{N}$, the expected net profit of each firm is $\frac{1}{N}[\phi \cdot(\sigma-1)+(1-\phi) \cdot 0]=\frac{\phi(\sigma-1)}{N}$. This is an equilibrium as long as undertaking the project without gathering any information does not yield higher net profits for any one deviating firm. That is, the equilibrium in which all firms gather information before deciding what to do with the project is possible as long as

$$
\frac{\phi(\sigma-1)}{N}>\sigma \phi-1
$$

or, equivalently, as long as $\sigma \phi<\frac{N-\phi}{N-1}$. This establishes part (ii) of the proposition, as well as the first portion of part (iii). The rest of part (iii) is established by showing that $\frac{\phi(\sigma-1)}{N} \geq \frac{\sigma \phi-1}{N}$, which is the case for all $\phi \leq 1$. Q.E.D.

This result tells us that projects for which $\sigma \phi \in\left(\frac{N-\phi}{N-1}, \infty\right) \subset(1, \infty)$ will never be investigated by competing firms, whereas all projects for which $\sigma \phi \in(0,1]$ are investigated by all firms. In the limit, as the number $N$ of firms in the industry increases (increasing competition), all projects with an expected payoff $\sigma \phi$ above 1 are undertaken before any additional information about them is gathered and, as in our model, only the projects with $\sigma \phi$ below 1 are further investigated. Q.E.D.

\section{Appendix C}

In this appendix, we formally derive the results that are discussed in Section III. Our first result is the analogue of Lemma 3 when the manager faces an effort cost $c>0$ with an exogenously specified contract $\left\{\delta_{\mathrm{M}}, \delta_{\mathrm{H}}\right\}$.

LEMMA C1: (i) Suppose that the manager's cost of effort is high in the sense that $c>\min \left[(a+b)(1-\phi) \delta_{\mathrm{M}},(a+b) \phi(1-r) \delta_{\mathrm{H}}\right]$. Then the manager never gathers information about the risky project, and he undertakes it if and only if

$$
\frac{\delta_{\mathrm{H}}}{\delta_{\mathrm{M}}} \geq \frac{1-\phi}{\phi(1-r)} .
$$

(ii) Suppose instead that the manager's cost of effort is low in the sense that $c \leq \min \left[(a+b)(1-\phi) \delta_{\mathrm{M}},(a+b) \phi(1-r) \delta_{\mathrm{H}}\right]$.

- If

$$
\delta_{\mathrm{H}} \leq \frac{\phi\left(1-\hat{\phi}_{\mathrm{U}}\right) \delta_{\mathrm{M}}+c}{\phi \hat{\phi}_{\mathrm{U}}(1-r)} \equiv \hat{\kappa}_{\mathrm{U}}\left(\delta_{\mathrm{M}}\right),
$$

then the manager never gathers information about the risky project and never undertakes it. 
- If

$$
\delta_{\mathrm{H}} \geq \frac{(1-\phi)\left(1-\hat{\phi}_{\mathrm{D}}\right) \delta_{\mathrm{M}}-c}{(1-\phi) \hat{\phi}_{\mathrm{D}}(1-r)} \equiv \hat{\kappa}_{\mathrm{D}}\left(\delta_{\mathrm{M}}\right),
$$

then the manager never gathers information about the risky project and always undertakes it.

- If $\hat{\kappa}_{\mathrm{U}}\left(\delta_{\mathrm{M}}\right)<\delta_{\mathrm{H}}<\hat{\kappa}_{\mathrm{D}}\left(\delta_{\mathrm{M}}\right)$, then the manager exerts effort to gather information about the risky project (i.e., $\tilde{s})$ and uses it to make his investment decision (i.e., he invests in the risky project if and only if $\tilde{s}=\sigma$ ).

Proof: The manager will only choose to gather information if this information affects his investment decision; that is, there is no point in paying the effort cost if he makes the same decision with $\tilde{s}=\sigma$ and $\tilde{s}=0$. Because $\hat{\phi}_{\mathrm{U}}>\hat{\phi}_{\mathrm{D}}$, if it is optimal for the manager to gather information, he will undertake the risky project if and only if $\tilde{s}=\sigma$. His expected utility from doing so is

$$
\begin{aligned}
\hat{\mathrm{E}}[\tilde{u}] & =\hat{\operatorname{Pr}}\{\tilde{s}=\sigma\} \hat{\operatorname{Pr}}\{\tilde{v}=\sigma \mid \tilde{s}=\sigma\}\left[\delta_{\mathrm{M}}+(1-r) \delta_{\mathrm{H}}\right]+\hat{\operatorname{Pr}}\{\tilde{s}=0\} \delta_{\mathrm{M}}-c \\
& =\phi \hat{\phi}_{\mathrm{U}}\left[\delta_{\mathrm{M}}+(1-r) \delta_{\mathrm{H}}\right]+(1-\phi) \delta_{\mathrm{M}}-c .
\end{aligned}
$$

Alternatively, the manager can choose to drop the risky project without acquiring any information about it. His expected utility from doing so is simply

$$
\hat{\mathrm{E}}[\tilde{u}]=\delta_{\mathrm{M}} .
$$

Finally, the manager can choose to undertake the risky project without acquiring any information about it. In this case, his expected utility is

$$
\hat{\mathrm{E}}[\tilde{u}]=\hat{\operatorname{Pr}}\{\tilde{v}=\sigma\}\left[\delta_{\mathrm{M}}+(1-r) \delta_{\mathrm{H}}\right]=\phi\left[\delta_{\mathrm{M}}+(1-r) \delta_{\mathrm{H}}\right] .
$$

The manager will exert effort to gather information if (C4) is greater than (C5) and greater than (C6). This is easily shown to be equivalent to $\hat{\kappa}_{\mathrm{U}}\left(\delta_{\mathrm{M}}\right)<$ $\delta_{\mathrm{H}}<\hat{\kappa}_{\mathrm{D}}\left(\delta_{\mathrm{M}}\right)$, where $\hat{\kappa}_{\mathrm{U}}\left(\delta_{\mathrm{M}}\right)$ and $\hat{\kappa}_{\mathrm{D}}\left(\delta_{\mathrm{M}}\right)$ are as defined in (C2) and (C3), respectively. It is easy to verify that $\hat{\kappa}_{\mathrm{U}}\left(\delta_{\mathrm{M}}\right)$ is greater than $\hat{\kappa}_{\mathrm{D}}\left(\delta_{\mathrm{M}}\right)$ for $\delta_{\mathrm{M}} \leq \frac{c}{(a+b)(1-\phi)}$ and smaller than $\hat{\kappa}_{\mathrm{D}}\left(\delta_{\mathrm{M}}\right)$ for $\delta_{\mathrm{M}} \geq \frac{c}{(a+b)(1-\phi)}$. As such, $\hat{\kappa}_{\mathrm{U}}\left(\delta_{\mathrm{M}}\right)<\delta_{\mathrm{H}}<\hat{\kappa}_{\mathrm{D}}\left(\delta_{\mathrm{M}}\right)$ is only possible when $\delta_{\mathrm{M}} \geq \frac{c}{(a+b)(1-\phi)}$ and $\delta_{\mathrm{H}} \geq \hat{\kappa}_{\mathrm{U}}\left(\frac{c}{(a+b)(1-\phi)}\right)=\hat{\kappa}_{\mathrm{D}}\left(\frac{c}{(a+b)(1-\phi)}\right)=\frac{c}{(a+b) \phi(1-r)}$. If $\hat{\kappa}_{\mathrm{U}}\left(\delta_{\mathrm{M}}\right)<\delta_{\mathrm{H}}<\hat{\kappa}_{\mathrm{D}}\left(\delta_{\mathrm{M}}\right)$ does not hold, the manager does not acquire any information and undertakes the risky project if and only if (C6) is greater than (C5), or, equivalently, if $\delta_{\mathrm{H}} \geq \frac{1-\phi}{\phi(1-r)} \delta_{\mathrm{M}}$ as in (C1). Otherwise, he drops the project. The rest of the proposition is proved by establishing that $\hat{\kappa}_{\mathrm{U}}\left(\delta_{\mathrm{M}}\right) \leq \frac{1-\phi}{\phi(1-r)} \delta_{\mathrm{M}} \leq \hat{\kappa}_{\mathrm{D}}\left(\delta_{\mathrm{M}}\right)$ for $\delta_{\mathrm{M}} \geq \frac{c}{(a+b)(1-\phi)}$, which is straightforward. Q.E.D.

The firm can only afford the manager's services if it can at least break even, after accounting for the compensation expense. More precisely, the firm can hire the manager only if the set of (IC) contracts includes at least one contract with which the firm's expected net profits are at least zero. The precise condition is derived in the following proposition. 
Proposition C1: Suppose that Assumptions 1 and 2 hold. The firm only hires the manager if the manager's cost of effort is sufficiently low in the sense that

$$
c<\frac{(a+b)(1-\phi)\left(1-\phi+\sigma \phi \phi_{\mathrm{U}}\right)(1-r)}{1-\phi+\phi_{\mathrm{U}}-r\left(1-\phi+\phi \phi_{\mathrm{U}}\right)} .
$$

Proof: At $\left\{\delta_{\mathrm{M}}, \delta_{\mathrm{H}}\right\}=\left\{\frac{c}{(a+b)(1-\phi)}, \frac{c}{(a+b) \phi(1-r)}\right\}$, the firm's expected net profits are given by

$$
\begin{aligned}
E[\tilde{\pi}]= & \operatorname{Pr}\{\tilde{s}=\sigma\} \operatorname{Pr}\{\tilde{v}=\sigma \mid \tilde{s}=\sigma\}\left(\sigma-\delta_{\mathrm{M}}-\delta_{\mathrm{H}}\right)+\operatorname{Pr}\{\tilde{s}=0\}\left(1-\delta_{\mathrm{M}}\right) \\
= & \phi \phi_{\mathrm{U}}\left(\sigma-\delta_{\mathrm{M}}-\delta_{\mathrm{H}}\right)+(1-\phi)\left(1-\delta_{\mathrm{M}}\right) \\
= & 1-\phi+\sigma \phi \phi_{\mathrm{U}}-\frac{c}{a+b}\left[\frac{\phi \phi_{\mathrm{U}}}{1-\phi}+\frac{\phi \phi_{\mathrm{U}}}{\phi(1-r)}+\frac{1-\phi}{1-\phi}\right] \\
= & 1-\phi+\sigma \phi \phi_{\mathrm{U}}-\frac{c}{(a+b)(1-\phi)(1-r)}\left[\phi \phi_{\mathrm{U}}(1-r)\right. \\
& \left.+(1-\phi) \phi_{\mathrm{U}}+(1-\phi)(1-r)\right] .
\end{aligned}
$$

This quantity is greater than zero if and only if (C7) is satisfied. Q.E.D.

Clearly, the right-hand side of (C7) is increasing in $b$. By committing him to exert effort, the manager's overconfidence makes him more attractive to the firm. Q.E.D.

\section{REFERENCES}

Adrian, Tobias, and Mark M. Westerfield, 2009, Disagreement and learning in a dynamic contracting model, Review of Financial Studies 22, 3873-3906.

Aggarwal, Rajesh K., and Andrew A. Samwick, 1999, Executive compensation, strategic competition, and relative performance evaluation: Theory and evidence, Journal of Finance 54, 1999-2043.

Agrawal, Anup, and Charles R. Knoeber, 1998, Managerial compensation and the threat of takeover, Journal of Financial Economics 47, 219-239.

Baker, George P., and Brian J. Hall, 2004, CEO incentives and firm size, Journal of Labor Economics 22, 767-798.

Baker, Malcolm, Richard S. Ruback, and Jeffrey Wurgler, 2007, Behavioral corporate finance, in B. Espen Eckbo, ed. Handbook of Corporate Finance: Empirical Corporate Finance (North-Holland, Amsterdam).

Barnea, Amir, Robert A. Haugen, and Lemma W. Senbet, 1985, Agency Problems and Financial Contracting (Prentice-Hall, Englewood Cliffs).

Baumann, Andrea O., Raisa B. Deber, and Gail G. Thompson, 1991, Overconfidence among physicians and nurses: The "micro-certainty, macro-uncertainty" phenomenon, Social Science and Medicine 32, 167-174.

Ben-David, Itzhak, John R. Graham, and Campbell R. Harvey, 2010, Managerial miscalibration, Working paper, Duke University.

Bernardo, Antonio, and Ivo Welch, 2001, On the evolution of overconfidence and entrepreneurs, Journal of Economics and Management Strategy 10, 301-330.

Billett, Matthew T., and Yiming Qian, 2008, Are overconfident CEOs born or made? Evidence of self-attribution bias from frequent acquirers, Management Science 54, 1037-1051. 
Brown, Rayna, and Neal Sarma, 2007, CEO overconfidence, CEO dominance and corporate acquisitions, Journal of Economics and Business 59, 358-379.

Campbell, T. Colin, Michael Gallmeyer, Shane A. Johnson, Jessica Rutherford, and Brooke W. Stanley, 2010, CEO optimism and forced turnover, Journal of Financial Economic forthcoming.

Christensen-Szalanski, Jay J., and James B. Bushyhead, 1981, Physicians' use of probabilistic information in a real clinical setting, Journal of Experimental Psychology: Human Perception and Performance 7, 928-935.

Cooper, Arnold C., Carolyn Y. Woo, and William C. Dunkelberg, 1988, Entrepreneurs' perceived chances for success, Journal of Business Venturing 3, 97-108.

Coval, Joshua D., and Anjan V. Thakor, 2005, Financial intermediation as a beliefs-bridge between optimists and pessimists, Journal of Financial Economics 75, 535-569.

Daniel, Kent, David Hirshleifer, and Avanidhar Subrahmanyam, 1998, A theory of overconfidence, self-attribution, and security market under and over-reactions, Journal of Finance 53, 1839-1885.

DeBondt, Werner F. M., and Richard H. Thaler, 1995, Financial decision-making in markets and firms: A behavioral perspective, in Robert A. Jarrow, Vojislav Maksimovic, and William T. Ziemba, eds. Handbooks in Operations Research and Management Science, Volume 9 (North-Holland, Amsterdam).

Diamond, Peter, 1998, Managerial incentives: On the near linearity of optimal compensation, Journal of Political Economy 106, 931-957.

Doukas, John A., and Dimitris Petmezas, 2007, Acquisitions, overconfident managers and selfattribution bias, European Financial Management 13, 531-577.

Dow, James, 2004, Is liquidity self-fulfilling? Journal of Business 77, 895-908.

Eckbo, B. Espen, and Karin S. Thorburn, 2003, Control benefits and CEO discipline in automatic bankruptcy auctions, Journal of Financial Economics 69, 227258.

Edmans, Alex, and Xavier Gabaix, 2009, Is CEO pay really inefficient? A survey of new optimal contracting theories, European Financial Management 15, 486-496.

Englmaier, Florian, 2006, A strategic rationale for having overconfident managers, Working paper, Harvard University.

Fershtman, Chaim, and Kenneth L. Judd, 1987, Equilibrium incentives in oligopoly, American Economic Review 77, 927-940.

Fischhoff, Baruch, 1982, Debiasing, in Daniel Kahneman, Paul Slovic, and Amos Tversky, eds. Judgment under Uncertainty: Heuristics and Biases (Cambridge University Press, Cambridge).

Frydman, Carola, 2005, Rising through the ranks: The evolution of the market for corporate executives, 1936-2003, Working paper, Harvard University.

Gabaix, Xavier, and Augustin Landier, 2008, Why has CEO pay increased so much? Quarterly Journal of Economics 123, 49-100.

Gervais, Simon, 2010, Capital budgeting and other investment decisions, in H. Kent Baker and John R. Nofsinger, eds. Behavioral Finance: Investors, Corporations, and Markets (Wiley and Sons, Hoboken, NJ).

Gervais, Simon, and Terrance Odean, 2001, Learning to be overconfident, Review of Financial Studies 14, 1-27.

Goel, Anand M., and Anjan V. Thakor, 2008, Overconfidence, CEO selection and corporate governance, Journal of Finance 63, 2737-2784.

Graham, John R., Campbell R. Harvey, and Manju Puri, 2009, Managerial attitudes and corporate actions, Working paper, Duke University.

Graham, John R., Si Li, and Jiaping Qiu, 2012, Managerial attributes and executive compensation, Review of Financial Studies forthcoming.

Hackbarth, Dirk, 2008, Managerial traits and capital structure decisions, Journal of Financial and Quantitative Analysis 43, 843-882.

Hall, Brian J., 2003, Six challenges in designing equity-based pay, Journal of Applied Corporate Finance 15, 21-33. 
Hall, Brian J., and Kevin J. Murphy, 2003, The trouble with stock options, Journal of Economic Perspectives 17, 49-70.

Heaton, J. B., 2002, Managerial optimism and corporate finance, Financial Management 31, 33-45.

Hirshleifer, David, 2001, Investor psychology and asset pricing, Journal of Finance 56, 1533-1597.

Hirshleifer, David, and Yoon Suh, 1992, Risk, managerial effort, and project choice, Journal of Financial Intermediation 2, 308-345.

Holmström, Bengt, 1979, Moral hazard and observability, Bell Journal of Economics 10, 74-91.

Holmström, Bengt, and Joan Ricart i Costa, 1986, Managerial incentives and capital management, Quarterly Journal of Economics 101, 835-860.

Jensen, Michael C., and William H. Meckling, 1976, Theory of the firm: Managerial behavior, agency costs and ownership structure, Journal of Financial Economics 3, 305-360.

Kaplan, Steven N., Mark M. Klebanov, and Morten Sorensen, 2008, Which CEO characteristics and abilities matter? Working paper, University of Chicago.

Kidd, John B., 1970, The utilization of subjective probabilities in production planning, Acta Psychologica 34, 338-347.

Kyle, Albert S., and F. Albert Wang, 1997, Speculation duopoly with agreement to disagree: Can overconfidence survive the market test? Journal of Finance 52, 2073-2090.

Lambert, Richard A., 1986, Executive effort and selection of risky projects, RAND Journal of Economics 17, 77-88.

Landier, Augustin, and David Thesmar, 2009, Financial contracting with optimistic entrepreneurs, Review of Financial Studies 22, 117-150.

Li, Feng, 2010, Managers' self-serving attribution bias and corporate financial policies, Working paper, University of Michigan.

Liu, Yue, and Richard Taffler, 2008, Damned out of their own mouths: CEO overconfidence in M\&A decision making and its impact on firm performance, Working paper, University of Edinburgh.

MacLeod, W. Bentley, and Daniel Parent, 1999, Job characteristics and the form of compensation, Research in Labor Economics 18, 177-242.

Malmendier, Ulrike, and Geoffrey Tate, 2005, CEO overconfidence and corporate investment, Journal of Finance 60, 2661-2700.

Malmendier, Ulrike, and Geoffrey Tate, 2008, Who makes acquisitions? CEO overconfidence and the market's reaction, Journal of Financial Economics 89, 20-43.

Manove, Michael, and A. Jorge Padilla, 1999, Banking (conservatively) with optimists, RAND Journal of Economics 30, 324-350.

Mehran, Hamid, 1995, Executive compensation structure, ownership, and firm performance, Journal of Financial Economics 38, 163-184.

Murphy, Kevin J., 1999, Executive compensation, in Orley Ashenfelter and David Card, eds. Handbook of Labor Economics (North-Holland Elsevier, Amsterdam).

Murphy, Kevin J., and Ján Zábojník, 2007, Managerial capital and the market for CEOs, Working paper, University of Southern California.

Neale, Margaret A., and Max H. Bazerman, 1990, Cognition and Rationality in Negotiation (The Free Press, New York, NY).

Oskamp, Stuart, 1965, Overconfidence in case-study judgments, Journal of Consulting Psychology 29, 261-265.

Palia, Darius, 2001, The endogeneity of managerial compensation in firm valuation: A solution, Review of Financial Studies 14, 735-764.

Palomino, Frédéric, and Abdolkarim Sadrieh, 2011, Overconfidence and delegated portfolio management, Journal of Financial Intermediation 20, 159-177.

Roll, Richard, 1986, The hubris hypothesis of corporate takeovers, Journal of Business 59, 197-216.

Ross, Stephen A., 1973, The economic theory of agency: The principal's problem, American Economic Review 63, 134-139.

Russo, J. Edward, and Paul J. H. Schoemaker, 1992, Managing overconfidence, Sloan Management Review 33, 7-17.

Sautner, Zacharias, and Martin Weber, 2009, How do managers behave in stock option plans? Clinical evidence from exercise and survey data, Journal of Financial Research 32, 123155 . 
Schaefer, Scott, 1998, The dependence of pay-performance sensitivity on the size of the firm, Review of Economics and Statistics 80, 436-443.

Sklivas, Steven D., 1987, The strategic choice of managerial incentives, RAND Journal of Economics 18, 452-458.

Staël von Holstein, Carl-Axel S., 1972, Probabilistic forecasting: An experiment related to the stock market, Organizational Behavior and Human Performance 8, 139-158.

Taylor, Shelley, and Jonathon D. Brown, 1988, Illusion and well-being: A social psychological perspective on mental health, Psychological Bulletin 103, 193-210.

Treynor, Jack L., and Fischer Black, 1976, Corporate investment decisions, in Stewart C. Myers, ed. Modern Developments in Financial Management (Praeger, New York, NY).

Wagenaar, Willem, and Gideoan B. Keren, 1986, Does the expert know? The reliability of predictions and confidence ratings of experts, in Erik Hollnagel, Giuseppe Mancini, and David D. Woods, eds. Intelligent Decision Support in Process Environments (Springer, Berlin).

Wang, F. Albert, 2001, Overconfidence, investor sentiment, and evolution, Journal of Financial Intermediation 10, 138-170.

Warner, Jerold B., Ross L. Watts, and Karen H. Wruck, 1988, Stock prices and top management changes, Journal of Financial Economics 20, 461-492.

Weisbach, Michael S., 1988, Outside directors and CEO turnover, Journal of Financial Economics 20, 431-460.

Yermack, David, 1995, Do corporations award CEO stock options effectively? Journal of Financial Economics 39, 237-269. 